\title{
EFEITO DO CORTE EM DIFERENTES PERIODOS E IDADES DE CRESCIMENTO SOBRE A PRODUÇÃO DE MATÉRIA SECA, ELIMINAÇĀO DE MERISTEMAS APICAIS, DESENVOLVIMENTO DO SISTEMA RADICULAR E VIGOR DA REBROTA DO CAPIM ANDROPOGON (Andropogon gayanus, KUNTH, VAR. BISQUAMULATUS).
}

NIVALDO ALVES DA COSTA

Orientador: Prof. Dr. MOACYR CORSI

Dissertação apresentada à Escola Superior de Agricultura "Luiz de Queiroz", da Universidade de São Paulo, para obtenção do título de Mestre em Nutrição Animal e Pastagens,

PIRACICABA

Estado de São Paulo - Brasil

Maio - 1982 
A meus pais

Antonio e Joana (in memoria)

MINHA GRATIDAOO.

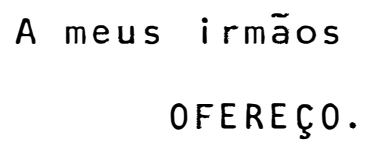

A minha esposa

Oneizilma e à

minha filha

Carolina

DEDICO. 


\section{AGRADECIMENTOS}

Ao Prof. Dr. Moacyr Corsi, pela eficiente orientação e amizade demonstrada na elaboração deste trabalho.

A Empresa de Assistência Técnica e Extensão Rural do Estado de Goiás - EMATER-Go, pela oportunidade que me foi conce dida para realização do curso de pōs-graduação.

Ao Prof. Dr. Celso Lemaire de Moraes, pelos ensinamentos e concessão do laboratōrio para anälises.

Aos Professores do Departamento de Zootecnia da ESALQ, pelos ensinamentos transmitidos.

Ao Eng? Agro Francisco lvaldo 01 iveira Melo e à Eng. Agr. Marinea de Lara Haddad pelo auxilio na interpretação da anālise estatística.

Ao Eng? Agr? Ronaldo Veloso Naves pelo auxilio na condução do experimento e solidariedade demonstrada durante o curso.

Ao Sr. José Machado Alves da Costa pelo apoio, amizade e dedicação. 
A Srta. Maria Elizabeth Ferreira de Carvalho pela colaboração nas referências bibliogräficas.

Aos funcionários da Biblioteca Central, em especial, aos Srs. Eurice Amaral Melo e Luís Carlos Veríssimo pela presteza demonstrada.

A Sr . Tekla E. Klar pelo eficiente serviço de datilografia.

Aos funcionários e estagiários do Departamento de Zootecnia, da ESALQ-USP, que direta ou indiretamente colaboraram pạ ra a realização deste trabalho. 


\section{INDICE}

Pāgina

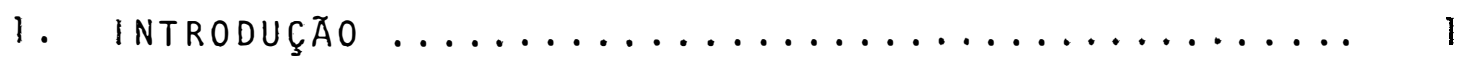

2. ReVISÃo de literatura $\ldots \ldots \ldots \ldots \ldots \ldots \ldots \ldots \ldots \ldots$

2.1. Produção de matéria seca $\ldots \ldots \ldots \ldots \ldots \ldots \ldots$

2.2. Elongação do meristema apical e vigor da re-

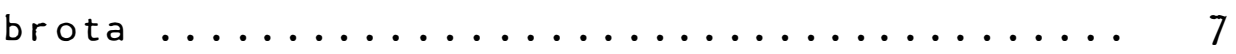

2.3. Perfilhamento em gramineas forrageiras..... 10 2.4. Influência da altura e frequência de cortes sobre o sistema radicular de forrageiras.... 13

3. MAterial e Metodos ..................... 16

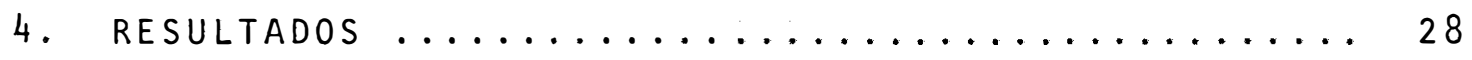

4.1. Produção de matéria seca $\ldots \ldots \ldots \ldots \ldots \ldots 28$

4.2. Variação no número total de perfilhos...... 32

4.3. Porcentagem de eliminação de meristemas api

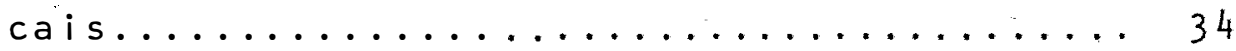


Pāgina

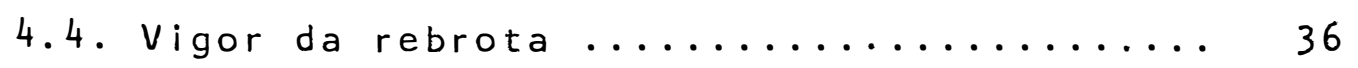

4.5. Altura e frequência de cortes $x$ sistema ra

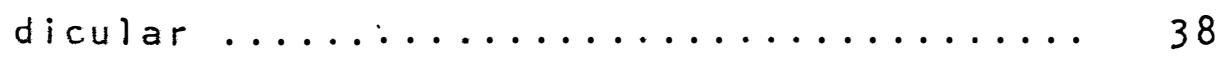

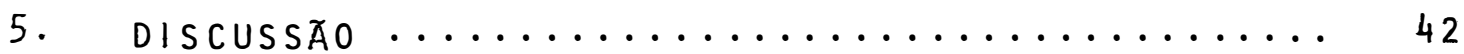

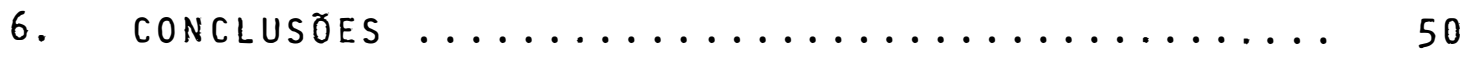

7. LITERATURA CITADA ..................... 52 
LISTA DE QUADROS

Pàgina

Quadro 1 - Esquema de condução do experimento no campo 18

Quadro 2 - Precipitação pluviométrica mm/dia durante o período experimental $\ldots \ldots \ldots \ldots \ldots \ldots$

Qua ro 3 - Esquema do cronograma das frequências e épo

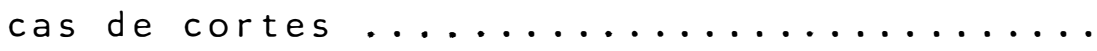

Quadro 4 - Análise da variância da produção de matéria seca do capim Andropogon.................

Quadro 5 - Efeito da idade e época de corte sobre a produção de matéria seca ( $\mathrm{kg} / \mathrm{ha}$ ) do capim Andropogon durante o período de outubro de 1981 a março de $1982 \ldots \ldots \ldots \ldots \ldots \ldots \ldots \ldots$

Quadro 6 - Análise da variáncia do número total de per filhos do capim Andropogon no período outubro 81 a março $82 \ldots \ldots \ldots \ldots \ldots \ldots \ldots$ 


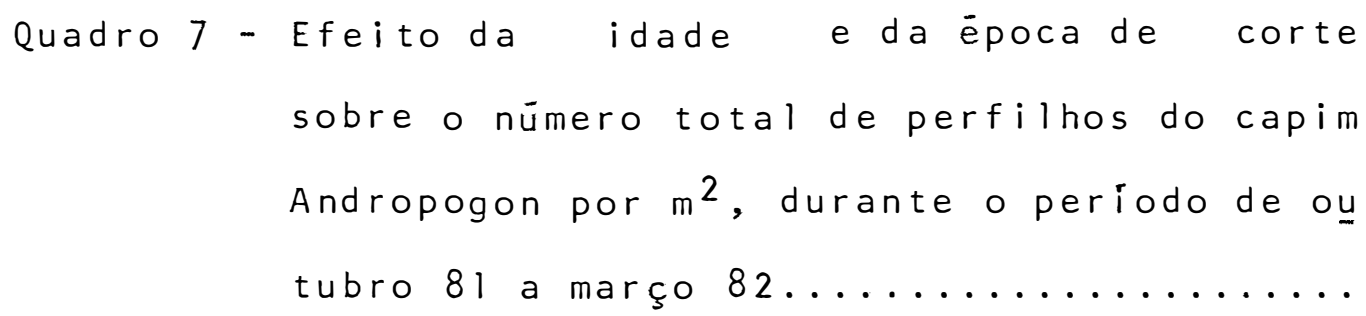

Quadro 8 - Análise da variância da porcentagem de el minação de meristemas apicais do capim Andropogon, cortado entre $10-15 \mathrm{~cm}$ do nivel

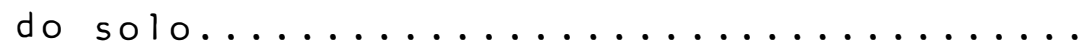

\begin{abstract}
Quadro 9 - Efeito da. idade
e época de corte sobre a porcentagem de eliminação de meristemas apicais do capim Andropogon, cortado

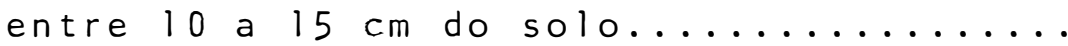

Quadro 10-Análise da variáncia para o vigor da re-

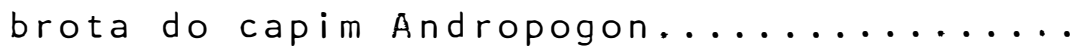

$$
\begin{aligned}
& \text { Quadro ll- Efeito da idade e ëpoca de corte sobre } \\
& \text { o vigor da rebrota (kg MS/ha) do capim Andro } \\
& \text { pogon, cortado entre } 10 \text { e } 15 \mathrm{~cm} \text { do solo.... }
\end{aligned}
$$


Quadro 12 - Anālise da variáncia para efeito da altura e frequência de cortes sobre a produção de matéria seca e sistema radicular

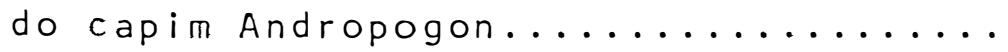

Quadro 13 - Efeito da altura e frequência de cortes sobre a produção de matēria seca da parte aérea (g/vaso) e peso total de matēria orgānica do sistema radicular (g/vaso) do capim Andropogon............ 40 


\title{
LISTA DE FIGURA
}

Pāgina

\begin{abstract}
Figura I - Efeito da idade sobre a produção de matëria seca do capim Andropogon colhido no periodo de outubro de 1981 a março de

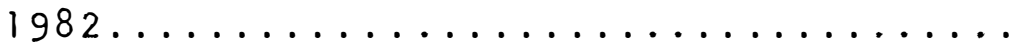


EFEITO DO CORTE EM DIFERENTES PERTODOS E IDADES DE CRESCIMENTO SOBRE A PRODUÇÃO DE MATERIA SECA, ELIMINAÇÃO DE MERISTEMAS APICAIS, DESENVOLVIMENTO DO SISTEMA RADICULAR E VIGOR DA REBROTA DO CAPIM ANDROPOGON (Andropogon gayanus, KUNTH, VAR. B ISQUAMULATUS).

Autor: Nivaldo Alves da Costa Orientador: Prof Dr. Moacyr Corsi

\section{RESUMO}

0 presente estudo, em diferentes periodos e idades de cortes, visou obter informações sobre a produtividade em matéria seca, a eliminação de meristemas apicais, o vigor da rebrota e sobre a influência da altura e frequência de cortes no sistema radicular do capim Andropogon (Andropogon gayanus, Kunth, var. bisquamulatus). os experimentos foram instalados junto ao Departamento de Zootecnia - ESALQ Piracicaba, em uma terra roxa estruturada. A adubação de plantio foi feita em sulcos distanciados de $0,5 \mathrm{~m}$ e constou de $120 \mathrm{~kg} \mathrm{P}{ }_{2} 0_{5}$ e $60 \mathrm{~kg} \mathrm{~K} \mathrm{~K}_{2}$ /ha e após cada corte, em cobertura, foi aplicado $80 \mathrm{~kg} \mathrm{~N}, 20 \mathrm{~kg} \mathrm{P}_{2} \mathrm{O}_{5}$ e $90 \mathrm{~kg} \mathrm{k} \mathrm{K}_{2} / \mathrm{ha}$, respectivamente sob a forma de nitrato de amônia, superfosfato sim ples e cloreto de potássio. A àrea experimental foi dividida em 4 sub-äreas com $112 \mathrm{~m}^{2}$ cada, sendo que cada sub-ärea correspondeu ao crescimento do mês (período). 0 delineamento ex- 
perimental usado foi inteiramente casualizado com 4 repetições e 7 idades de corte. A altura de cortes empregada foi de $10-15$ cm acima do nivel do solo. A produção de matéria seca foi determinada, coletando o material contido em $1 \mathrm{~m}^{2}$. Após a coleta, o material foi secado em estufa com ventilação forçada até peso constante. Esta àrea foi demarcada para posterior determinação da porcentagem de eliminação de meristemas apicais e vigor da rebrota. Os resultados permitiram concluir que; a produtividade do capim Andropogon aumenta diretamente com a idade. Cortes efetuados a cada 30 dias reduz drasticamente a produtividade de matéria seca da parte aērea, mas não se observou o mesmo efeito para a altura de corte que variou de 5 e 20 cm. O desenvolvimento do sistema radicular ë prejudicado tanto pela frequência como pela altura de corte. 0 capim Andropogon apresenta alongamento tardio das hastes. Trata-se de uma graminea extremamente exigente em relação ao manejo, fator que pode limitar o sucesso das recomendações para a utilização desta planta forrageira em condições de solos pouco férteis e àcidos. A maior produtividade e persistência desta graminea, provavelmente, serão obtidas através de cortes ao redor de 40 dias e a altura de cerca de $15 \mathrm{~cm}$. 
CUTTING EFFECT ON DIFFERENT PERIODS AND GROWTH STAGES ON DRY MATTER PRODUCTIVITY, PERCENTAGE OF APICAL MERISTEM ELIMINATION, ROOT GROWTH AND REGROWTH VIGOR ON Androgopong gayanus, KUNTH, VAR. BISQUAMULATUS GRASS.

Author: Nivaldo Alves da Costa. Adviser: Prof. Dr. Moacyr Corsi

\section{SUMMARY}

The effect of growth stages, and date of cuttings on dry matter productivity, percentage of apical meristem elimination, root growth and regrowth vigor was studied with Andropogon gayanus Kunth, var. bisquamulatus. Trials were conducted in the field and on pots during the growth period (october-march) during 1981-1982 at Piracicaba, SP, in the Central part of Brazil. The field experiment was established on a fertil tropudalf soil known as "terra roxa estruturada". The grass was established with an application of $120 \mathrm{~kg} \mathrm{P}{ }_{2}{ }_{5}$ and $60 \mathrm{~kg} \mathrm{~K} \mathrm{~K}_{2} \mathrm{O} / \mathrm{ha}$. Twenty eigth treatments (four dates of growth combined to seven weekly cutting intervals) and fours replicates were used in a completely randomized design. Four plots, each representing a date of growth were cut for uniformization at 28 days intervals. Plots were fertilized after each cut with $80 \mathrm{~kg} \mathrm{~N}, 20 \mathrm{~kg} \mathrm{P}_{2} \mathrm{O}_{5}$ and $90 \mathrm{~kg} \mathrm{~K} \mathrm{~K}_{2} \mathrm{o} / \mathrm{ha}$; then it was established in one plot the date of cutting and the 
weekly harvesting intervals up to seven weeks. Meanwhile other plots grew up to the next uniformization cut when a new fertilization and date of cutting was set. The effect of frequency ( 30 days and 45 days of cutting intervals) and height of cuttings $(5 \mathrm{~cm}$ and $20 \mathrm{~cm}$ ) on dry matter production and root growth was studied on plants established in pots. Four replicates were used in a completely randomized design. The results of these experiments allow the following conclusions: Andropogon gayanus grass productivity increased directly with maturity. Frequent cuttings (30 days intervals) reduced drastically dry matter production of this grass but height of cutting ( $5 \mathrm{~cm}$ and $20 \mathrm{~cm}$ ) did not affect it. Root growth of Andropogon grass is reduced by height and frequency of cuttings studied. Percentage of apical meristems eliminated during aproximately 150 days of experimental period was low which would suggest that stem elongation is late on this grass. Andropogon gayanus seems to have a high requirement of management in relation to frequency and height of cutting. This fact should be of importance since this grass has been recommended to be utilized on acid and infertil soils where lack of management would have severe consequences. Andropogon's stand persistence and high productivity may be obtained when cuts are made around 46 days at $15 \mathrm{~cm}$ high. Filed results may be influenced by the frequency of uniformization cuts (28 days) since the pot experiment showed that Andropogon's persistence and productivity are affected by hight and cutting frequency. 
1. INTRODUÇÃO

o rebanho brasileiro è mantido quase que exclusivamente em regime de pasto. 0 apascentamento desses animais ocorre em pastagens naturais e artificiais. Segundos dados do Instituto Brasileiro de Geografia e Estatistica (1980), $25 \%$ da àrea dos estabelecimentos agropecuārios (3.238.960,32ha) está coberta por pastagens onde as naturais contribuem com $17,4 \%$. $(125.950 .884 \mathrm{ha})$ e as cultivadas com $7,6 \%$ (39.701.366 ha).

As plantas forrageiras são, basicamente, a fonte mais econômica para fornecer alimentos aos herbívoros. A sua produção é grandemente afetada pela fertilidade do solo, condições climäticas e manejo a que são submetidas.

Elevadas produções e altos valores nutritivos são caracteristicas que dependem das espécies vegetais e dispo 
nibilidade dos fatores de crescimento. Uma mesma espécie forra geira pode ter valores diferentes na sua composição e produção de matéria seca em função do manejo adotado. A obtenção da māxima produção com melhor valor nutritivo sem, contudo, comprometer a perenidade da pastagem, são os objetivos primordiais em um programa de manejo de plantas forrageiras. Tais ob jetivos são dependentes da morfologia e fisiologia da espécie utilizada, da altura e frequência de cortes a que são submetidas, bem como do estádio vegetativo da planta por ocasião da colheita.

Diversos pesquisadores evidenciaram o efeito da altura e frequéncia de cortes sobre a produtividade e persistēncia de plantas forrageiras (LANGER, 1959; PAULA et alii, 1969). Porém, CoRSI (1972) afirma que outro fator importante na determinação da frequéncia de corte é a qualidade da forragem colhida. Altos rendimentos e valores nutritivos estão negativamente correlacionados, devendo-se procurar através do manejo obter a maior produção de matéria seca com o menor prejuizo do valor nutritivo.

As regiões tropicais são caracterizadas, principalmente, pela elevada acidez e baixo teor de nutrientes em seus solos, dificultando sensivelmente a produção de forragens. No Brasil, essas regiões são contempladas com 120 milhões de hectares cobertas por vegetação de cerrado, constituindo - se 
em um potencial para a produção de plantas forrageiras. Esses solos apresentam, em sua maioria, baixo pH, 4,3-4,5, alta saturação de alumínio, I 50\% (GOEDERT, 1979); alta fixação de fósforo, atingindo níveis de 750 ppm (Centro Internacional de Agricultura Tropical, 1978); e baixos teores de nutrientes, principalmente fósforo, 0,4 ppm (GALRÃO e LOPES, 1979), Iimitando a produtividade das pastagens e o desempenho animal. 0 uso de espécies forrageiras tolerantes a essas condições, como è o caso do capim Andropogon gayanus podem constituir-se em a! ternativas viāveis para a incorporação dessas āreas à produção pecuāria.

o presente estudo com capim Andropogon (Andropogon gayanus, Kunth var. bisquamulatus) tem por objetivos: obter informações sobre a produção de matéria seca, tendo a gramínea a mesma idade cronológica em diferentes períodos durante a estação de crescimento; verificar o ritmo e época de elongação do meristema apical; obter informações sobre o vigor da rebrota; verificar possiveis influencias da altura e frequência de cortes sobre o sistema radicular. 


\section{REVISÃO DE LITERATURA}

A graminea Andropogon gayanus, originäria da Africa Central, apresenta-se como espécie tolerante solos àcidos e de baixa fertilidade (OTERO, 1952 e JONES, 1979). Entretanto, aumento na produção de matéria seca da planta forrageira está diretamente relacionada com aplicação de níveis cres centes de fósforo até a dosagem de $234 \mathrm{~kg} \mathrm{P}{ }_{2}{ }_{5} / \mathrm{ha}$, de acordo com THOMAS et alii (1981). Pode ser estabelecida em consórcio com culturas anuais (HAGGAR, 1969), è resistente à seca (EMRICH, 1967 e BOGDAN, 1977), tolerante ao fogo (Centro Internacional de Agricultura Tropical, 1979), resistente às cigarrinhas-daspastagens e boa aceitabilidade pelos animais (THOMAS et ali $i$, $1981)$.

\section{1. Produção de matéria seca.}

A produtividade de uma planta forrageira, de- 
pende de seu potencial genético, dos fatores de crescimento e manejo adotado. As gramíneas forrageiras tropicais têm demonstrado elevada capacidade produtiva, podendo esta ser prejudicada pela forma de plantio. BOWDEN (1963a), comparando. a produção de matēria seca do Andropogon gayanus cultivado em linhas a lanço e plantas espaçadas, obteve produções de 7310,6578 e $5815 \mathrm{~kg}$ MS/ha para cada sistema de plantio, respectivamente. outro fator determinante na produtividade das forrageiras é a altura e frequência de cortes. BOGDAN (1977) variando a frequên cia de corte em Andropogon gayanus obteve produções de 10.000 e $14.000 \mathrm{~kg}$ MS/ha quando a gramínea foi cortada 12 e 7 vezes ao ano, a uma altura de $10 \mathrm{~cm}$ do nível do solo, respectivamente.

Andropogon gayanus produz nos mais variados t pos de solo e responde bem ao uso de fertilizantes. Em condições de precipitação anual superior a $600 \mathrm{~mm}$, HAGGAR (1975) observou aumento na produção de matéria seca de Andropogon da ordem de $14,4 \mathrm{~kg}$ para cada kg de nitrogênio aplicado até atingir $28 \mathrm{~kg} \mathrm{~N} / \mathrm{ha}$. Porém, a mäxima produção de matēria seca (12.000 kg/ha), foi obtida com a aplicação de $112 \mathrm{~kg} N / h a$ no terceiro ano de avaliação da forrageira. Para verificar a capacidade de resposta do Andropogon gayanus ao uso de adubos nitrogenados em solos de baixo pH, trabalhos experimentais no CIAT (1979), compararam as produções da referida graminea com Panicum maximum e Brachiaria decumbens. Todas as plantas forrageiras foram aduba- 
das com $200 \mathrm{~kg} \mathrm{P}_{2} \mathrm{O}_{5} / \mathrm{ha} / \mathrm{ano}$. Foi observado que no nivel zero de nitrogênio o A. gayanus produziu $7.500 \mathrm{~kg} M S / h a$, enquanto que as demais gramineas produziram 3.800 e $4.000 \mathrm{~kg} \mathrm{MS} / \mathrm{ha}$, respectivamente. Nestes trabalhos, A. gayanus e B. decumbens mostraram um melhor comportamento a condições de baixa fertilidade em nitrogênio e fósforo. Usando adubação $N$, $P$ e $K(67 \mathrm{~kg} \mathrm{~N}$, $89 \mathrm{~kg} P_{2} 0_{5}$ e $\left.45 \mathrm{~kg} \mathrm{~K} 20 / \mathrm{ha}\right)$, durante dois anos, ASARE (1974) obteve produções de 28.000 e $20.000 \mathrm{~kg} \mathrm{MS} / \mathrm{ha}$, respectivamente, no primeiro e segundo ano. SINGH et alii (1972) comparando a produção do híbrido Pearl-Millet-Napier com Pennisetum polystachyum, P. pedicelzatum, Andropogon gayanus e Brachiaria brizantha, adu bados com $114 \mathrm{~kg} \mathrm{~N}$ e $46 \mathrm{~kg} \mathrm{P}_{2} \mathrm{O}_{5} / \mathrm{ha} / \mathrm{ano}$, obtiveram produção de $703 \mathrm{~kg}$ MS/ha/semana para A. gayanus, enquanto as demais forrageiras produziram, respectivamente, $245,391,413,687 \mathrm{~kg} M \mathrm{~S} / \mathrm{se}-$ mana. Em pastagem estabelecida de Andropogon, pastejada no ano anterior e adubada com $35 \mathrm{~kg} \mathrm{P}_{2} \mathrm{O}_{5}$ /ha antes do ensaio. HAGGAR (1970) obteve produção de $3.000 \mathrm{~kg}$. MS /ha no mês de outubro. Em solo argilo-arenoso na região tropical da India, SINGH e CHATTERJEe (1966), trabalhando com diversas forrageiras obtiveram produção de $1.321 \mathrm{~kg}$ MS/ha para Andropogon gayanus. Estudan do a produção de várias gramíneas forrageiras em solo Podzólico Vermelho amarelo var. Laras, PEDREIRA et alii (1975) constatạ ram produção de $18.070 \mathrm{~kg}$ MS/ha para A. gayanus, superando todas as espécies estudadas, exceto Panicum maximum. Pesquisando em um Latossol Vermelho escuro de cerrado, a EMPRESA GOIANA DE PESQUISA AGROPECUARIA (1979) relata produção de $12.000 \mathrm{~kg}$ 
MS/ha para A. gayanus fertilizado com $30 \mathrm{~kg} \mathrm{~N}, 300 \mathrm{~kg} \mathrm{P}{ }_{2} \mathrm{O}_{5}, 100$ $\mathrm{kg} \mathrm{K}_{2} \mathrm{O}$ e $50 \mathrm{~kg} \mathrm{ZnSO} 4 / \mathrm{ha}$. Em Nova Odessa, ALCANTARA e BUfArAH (1979) obtiveram igual produção $(12.000 \mathrm{~kg}$ MS/ha) para a referida forrageira. Em solo arenoso, EgUNJobI (1973) obteve para A. gayanus, taxa média de crescimento de 176 a $270 \mathrm{~kg}$ MS/ha/dia durante o verão.

$$
\text { Uma das causas da baixa produtividade animal }
$$

no Brasil é a estacionalidade de produção das plantas forrageiras. 0 uso de pastagens consorciadas tem sido apontado como alternativa para amenizar a escassez de for ragem durante o período critico de produção das pastagens. Andropogon gayanus è uma espécie de graminea forrageira de fácil consorciação com Cen trosema sp (JONES, 1979), Zornia Zatifolia e Pueraria phaseoloides (Centro Internacional de Agricultura Tropical, 1980), Styzosanthes guianensis e Centrosema pubescens (GROF, 1981) e com Macroptilium atropurpureum (THOMAS et alii, 1981). Na Colombia GROF (1981) trabalhando com a associação de A. gayanus com S. guianensis e C. pubescens obteve a produção de 15.300 e 18.710 kg MS/ha/ano, respectivamente, quando submetida a intervalos de cortes de 45 dias e altura de $15 \mathrm{~cm}$, em solos ácidos e adubados com $80 \mathrm{~kg} \mathrm{P} \mathrm{O}_{5} / \mathrm{ha}$.

\subsection{Elongação do meristema apical e vigor da rebrota.}

A velocidade de recuperação das gramíneas forra- 
geiras apös o corte ou pastejo depende, principalmente, da localização do seu meristema apical em relação ao nível do solo. por ocasião da colheita e, consequentemente, da altura de corte a que foi submetida. o rítmo de elongação do meristema apical das espécies forrageiras é determinado por fatores genéticos e ambientais.

A taxa de eliminação de meristema apical das principais forrageiras de clima tropical em função da idade jā foi objeto de estudo de vários pesquisadores. PEDREIRA e BOIN (1969) observaram que após 63 dias de crescimento vegetativo e cortado a $10 \mathrm{~cm}$ acima do nivel do solo, $61 \%$ dos meristemas apicais do Napier foram eliminados, enquanto ANDRADE e GOMIDE(1971) constataram $100 \%$ de eliminação dos meristemas aos 56 dias de vegetação. TARDIN et alii (1971) observaram no Capim-Guatemala (Tripsacum spp) $28,5 \%$ de eliminação de meristema apical quando

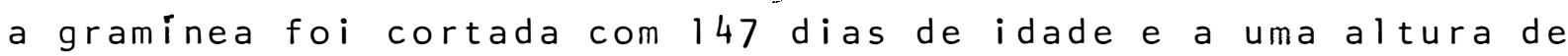
$10 \mathrm{~cm}$ acima do nível do solo. NASCIMENTO Jr. e PINHEIRO (1975) encontraram $41 \%$ de eliminação do meristema apical em capim-Jaraguá, quando a planta tinha 112 dias de idade, enquanto que BOTREL (1980) trabalhando com a mesma forrageira encontrou $88 \%$ de eliminação de seus meristemas apicais quando a gramínea estava com 70 dias de idade e cortada a $5 \mathrm{~cm}$ acima do nivel do solo. Capim gordura (Melinis minutiflora) e Capim-buffel tiveram 100\% de seus meristemas apicais eliminados quando cortados com 60 dias de idade (NASCIMENTO, 1977). GOMIDE et alii (1979) estu- 
dando os fatores morfofísiológicos de rebrota do capim-colonião (Panicum maximum, Jacq.), observaram que aos 49 dias de idade e cortado a $15 \mathrm{~cm}$ do solo, $43 \%$ dos meristemas apicais foram elimi nados.

Segundo BOOYSEN et alii (1963), uma vez eliminado o meristema apical não mais serão produzidas folhas neste perfilho e o crescimento vegetativo é diminuido até que novos perfilhos sejam desenvolvidos através de gemas axilares ou basais. Entretanto, CoRS। (1972) afirma que a eliminação do meris tema apical parece não constituir problemas para espécies que tem poder elevado de recuperação através do perfil hamento.

A produtividade, o valor nutritivo e a persistência da planta forrageira podem ser alterados pela velocidade de recuperação das espécies após a desfolha. Para DAVIDSON e MILTHORPE (1966a), a recuperação das plantas forrageiras após a defoliação, depende do desenvolvimento da superficie fotossintética. Sendo, porém, a velocidade de rebrota influenciada por certas caracteristicas morfofisiológicas que as plantas apresentam por ocasião do corte, além, de o serem pelas condições ambientais. Das inerentes à fisiologia, destacam-se indice de àrea foliar remanescente (HUMPHREYS e ROBISON, 1966; VILELA et alii, 1978), posição do meristema apical em relação ao plano de corte (BOOYSEN et alii, 1963; ANDRADE e GOMIDE, 1971; TARDIN et alii, 1971; NASCIMENTO Jr. e PINHEIRO, 1975; GOMIDE 
et alii, 1979; BOTREL, 1980) e niveis de reservas de carboidratos acumulados na base do caule e sistema radicular (BROWN e BLASER, 1970; ARAOJO e JACQUES, 1974). Entre os fatores ambientais que influenciam a recuperação das plantas forrageiras, a interceptação de luz pelas folhas demonstrou uma relação direta com a taxa de rebrota (BROUGHAM, 1956).

As maiores produções de matēria seça da rebrota são obtidas quando se efetua a defoliação, preservando a maior sobrevivência dos meristemas apicais. GOMIDE et alii (1979) evi denciaram tal fato em estudo realizado com capim-colonião. 0 efeito da sobrevivência dos meristemas apicais no vigor da rebrota, segundo GOMIDE (1973) é devido à räpida reconstituição da área foliar nas plantas que não os tiveram eliminados, deixando-as em condições favorāveis para uma mais eficiente interceptação da luz solar. Em capim rhodes (ChZoris gayana, Kunth), DOVRAT et alii (1980), relatam que a capacidade de rebrota da gramínea após o corte está relacionada com o estägio de desenvolvimento dos perfilhos.

\subsection{Perfilhamento em gramineas forrageiras.}

As principais familias empregadas na formação de pastagens são as gramíneas e leguminosas. Há um maior emprego das gramíneas graças ao seu elevado potencial produtivo e alta capacidade de perfilhamento. Na formação de pastagens, atenção 
deve ser dispensada para o uso de espécies com elevada capacidade de perfilhamento, pois, o solo é mais rapidamente coberto evitando a erosão e a concorrência de invasoras. Na planta for rageira, segundo JEWISS (1972), o perfilhamento desemepnha as funções de auxiliar o estabelecimento e assegurar a perenidade da espécie. A capacidade de perfilhamento pode aumentar a produção de matéria seca (CORSI, 1972), reduzir o teor de sacarose em cana de açücar (MALAVoltA et alii, 1964), ou determinar o espaçamento de certas culturas (CORSI, 1972).

o perfilhamento, segundo LEOPOLD (1949) parece estar sob controle hormonal regido pela dominància apical. Uma vez eliminado o meristema apical, o perfilhamento ocorrerá por meio de gemas basais e laterais, (BOOYSEN et alii, 1963). A formação de perfilhos, desde que não haja fator limitante, é exponencial. De acordo com LANGER (1963), o perfilhamento em gramineas forrageiras è influenciado por diversos fatores ambientais e genéticos. SINGH e CHATERJEe (1966), estudando o perfilhamento de diversas grạ mineas forrageiras nos tröpicos indianos, afirmam que os fatores de crescimento, luz, temperatura e umidade do solo são essenciais para o perfilhamento, porém, com a continua disponibilidade desses fatores, ocorre o alongamento e desenvolvimento desses perfilhos, reduzindo, mais tarde, a atividade de perfilhamen to da planta. Estudando os hábitos de perfilhamento do capim cocolinão, vegetando sem a interferência de corte ou adubação, PE- 
DREIRA (1975) verificou que no fim da primavera até o começo do veräo ocorreu o maior indice de perfilhamento.

o crescimento vegetativo das espécies só ocorre em temperaturas favoráveis, sendo esta variável de espécie para espécie (FERRAZ, 1974). Mas para DEINUM e DIRVEM (1972), - efeito da temperatura sobre o perfilhamento não pode ser con siderado isolado. Baixa temperatura deve ser acompanhada de baixa intensidade de luz (LANGER, 1972). Entretanto, se a temperatura for elevada, o perfilhamento pode ser prejudicado, face ao aumento na taxa de respiração (BROWN e BLASER, 1970).

As plantas que necessitam da luz para a sua sobrevivência, são dependentes da sua qualidade, duração e intensidade (MAGALHÃES, 1979). O perfilhamento, segundo VARTHA (1973) è grandemente afetado pelo sombreamento; podendo estimular o desenvolvimento de perfilhos laterais em napier, conforme observação feita por CoRSI (1972), que supõe o não aparecimento de perfilhos basais devido ao sombreamento feito pela ärea foliar remanescente após o corte.

As forrageiras têm como suporte para o seu desenvolvimento o solo que, normalmente, é pobre em nutrientes. De acordo com MALAVOLTA (1980), $90 \%$ das análises de amostras de solo realizadas no Brasil apresentam deficiència de fósforo. Este macronutriente desempenha papel fundamental no armaze- 
namento e fornecimento de energia necessária para os processos vitais da planta. 0 uso de adubos nitrogenados em pastagens, no nosso meio, ainda é uma prática de manejo de plantas forrageiras pouco difundida. O nitrogênio é o principal constituinte das proteínas que são as responsāveis pela formação de novas brotaçöes. 0 uso de adubaçöes nitrogenadas em gramíneas forrageiras, de acordo com WILSON e HAYDOCK (1971) elevam o nūmero de perfilhos e aumentam os seus pesos.

\subsection{Influência da altura e frequência de cortes sobre o sistema radicular de forrageiras.}

Quando a planta forrageira tem todo o seu tecido fotossintetizante removido pelo corte ou pastejo, a sua recuperação fica às expensas das reservas previamente armazenadas. os örgãos de armazenamento são variāveis conforme a espécie. Segundo GOMIDE (1973) basicamente são constituídos por raízes, rizomas, estolhos e base do caule.

os compostos que constituem as substâncias de reservas têm sido preocupação de vários pesquisadores. Para WHITE (1973) as reservas são constituídas de carboidratos não estruturais, enquanto que MAY (1960) considera sacarose, frutose e amido como compostos de reservas e que as espécies que acumulam frutosanas são nativas de clima frio ou temperado e as que armazenam açūcar e amido são de clima quente. As reser- 
vas orgânicas têm värias finalidades na vida da planta. Segundo WHITE (1973) tais reservas são usadas como fonte de energia para a iniciação de novos crescimento atè que a fotossíntese seja suficiente para equilibrar a respiração da planta. Mas em Dactyzis gromerata sob defoliaçöes continuas, DAVIDSON e MILTHORPE (1966) observaram mobilização de outras substâncias,provavelmente proteinas, para promover a respiração e novos crescimentos. Porēm, WHITE (1973) afirma que os compostos nitrogenados possam ser utilizados na respiração mas, éles não são tão importantes quanto os carboidratos para a rebrota.

Assim como as substâncias de reservas têm sido preocupação de vários pesquisadores, a distribuição do sistema radicular, um dos örgãos armazenadores, têm merecido atenção de muitos estudiosos. WHYTE (1969) afirma que a profundidade máxima das raízes varia com a espécie, tipo de solo e nível freático, e que, a maioria das gramíneas de clima temperado úmido tem mais de $60 \%$ do peso seco total das raízes nos primeiros $10 \mathrm{~cm}$ de profundidade. Pennisetum clandestinum tem $75 \%$ do seu sistema radicular nos primeiros $60 \mathrm{~cm}$ de profundidade (HOSEGOOD, 1963); Lolium perene e Pennisetum purpureum, Schum, tem $81 \%$ e $80 \%$, res pectivamente, nos primeiros $20 \mathrm{~cm}$ de profundidade (EVANS, 1978 e LIMA et alii, 1976). Em Andropogon gayanus o sistema radicular foi pesquisado por BOWDEN (1963b) que observou uma distribuição a profundidades superiores a $100 \mathrm{~cm}$. 
o desenvolvimento do sistema radicular

pode ser afetado por uma série de fatores. GARGANTINI (1972) afirma que se uma planta ao se desenvolver encontra uma camada com pe quena ou nenhuma acidez e, em seguida, outra camada de solo àcido, esta terá o sistema radicular desenvolvido deficientemente. Grama bermuda tem o desenvolvimento das raízes afetada pela presença de alta acidez no solo (MALAVOLTA, 1976). Em solos com pH em torno de 3,0 e com mais de 1,0 miliequivalente de alumínio trocável por $100 \mathrm{~g}$ de solo, este é potencialmente tóxico para o desenvolvimento da planta, concluiu o autor. A presença de manganês também prejudica o desenvolvimento do sistema radicular (BARBER, 1966). Embora a àgua seja indispensāvel a qualquer processo químico ou biológico no solo, as ra zes suportam seu excesso tão mal quanto a escassez (PRIMAVESI, $1980)$.

O sistema radicular é grandemente afetado por cortes baixos e frequentes (DOVRAT et alii, 1980; CORREA, 1981) - que prejudica sensivelmente a produção da parte aérea. PAULA et alii (1969) trabalhando com Melinis minutiflora, verificaram que o peso seco total das raízes foi afetado pela altura e frequência de cortes. DOVRAT et ali $(1980)$ observaram em capim rhodes que o peso das raízes diminuiu drasticamente após o corte quando a forrageira passava por um longo periodo de descanso. Estudando o efeito do intervalo e número de cortes sobre o peso das raízes do capim jaraguá após diferentes rempos de rebrota, CORREA (1981) observou que quanto mais frequentes os cortes, menores foram os pesos do sistema radicular. 
3. MATERIAL E METODOS

\section{Experimento}

0 experimento foi instalado em $11 / 11 / 1980$ no

Departamento de Zootecnia da Escola Superior de Agricultura "Luiz de Queiroz" (ESALQ), em ärea anteriormente coberta por soja perene (Neotonia wightii). A coleta de dados, entretanto, foi iniciada cerca de um ano apōs o estabelecimento da planta forrageiras com a finalidade de permitir avaliações durante todo o periodo de crescimento sem efeitos prejudiciais de fotoperiodo, temperatura e umidade que ocorreriam se os dados fossem coletados no ano da semeadura. As principais caracterís ticas quimicas do solo foram determinadas pelo laboratório de Quimica e Fertilidade do Solo da ESALQ, apresentando os seguin tes resultados: $\mathrm{pH}=5,6 ; \%$ Carbono $=2,07 ; \mathrm{P}=24 \mathrm{ppm} ; \mathrm{K}=$ $281 \mathrm{ppm} ; \mathrm{Al}^{+++} 1 \mathrm{Traços} ; \mathrm{Ca}=6,88 \mathrm{~m} . \mathrm{eq} / 100 \mathrm{~g} ; \mathrm{Mg}=2,84 \mathrm{~m} . \mathrm{eq} / 100 \mathrm{~g}$. Após o preparo do solo que consistiu em uma aração e duas gradagens, procedeu-se a abertura dos sulcos de plantio, distanciados de $50 \mathrm{~cm}$. Os sulcos foram abertos com uma se- 
meadeira "Jumil" de tração motorizada, efetuando-se simultanea mente a adubação na base de 120 e $60 \mathrm{~kg} /$ ha de $\mathrm{P}_{2}{ }^{\mathrm{O}_{5}}$ e $\mathrm{K}_{2} \mathrm{O}$, respectivamente, sob a forma de superfosfato simples e cloreto de potássio. Em seguida, procedeu-se a distribuição manual das sementes nos sulcos previamente adubados, e a uma profundidade aproximada de $3 \mathrm{~cm}$. A quantidade de sementes empregada foi de aproximadamente $8 \mathrm{~kg} / \mathrm{ha}$.

Transcorridos 17 dias do plantio, observou-se na ärea grande infestação de invasoras. No dia $28 / 11 / 1980$ procedeu-se a primeira capina efetuada manualmente com enxada, tendo o cuidado de deixar o material cortado entre os sulcos de plantio. Nessa ocasião não se observou inicio de germinação que só ocorreu no dia 19/12/1980. Após a emergência das plântulas, ou seja, dia $27 / 12 / 1980$, observou-se novamente na ärea grande incidencia de invasoras, tendo predominância as de folhas largas. Nessa data efetuou-se o controle quimico das invasoras, usando 2-4-D-amina na dosagem de 2 litros/ha, aplicado com pulverizador costal de barra dupla. No dia 08/01/1981, procedeu-se a uma segunda capina, eliminando as invasoras remanescentes, favorecendo a consolidação da gramínea. Os dados de pre cipitação pluviométrica, durante o período experimental, é dado na Tabel'a 1 .

A área total plantada foi de $5.000 \mathrm{~m}^{2}$, da qual demarcou-se $480 \mathrm{~m}^{2}$ em local onde o "stand" era mais uniforme para a condução do experimento. O experimento foi conduzido em 4 períodos diferentes, a saber: outubro a dezembro de 1981 , 
novembro de 1981 a janeiro de 1982, dezembro de 1981 a fevereiro de 1982 e janeiro a março de 1982. Para cada período foi de1 imitada uma ārea de $112 \mathrm{~m}^{2}$, dividida em 28 parcelas de $4 \mathrm{~m}^{2}$ cada, conforme esquema dado no Quadro 1. QUADRo 1 - Esquema de condução do experimento no campo

\begin{tabular}{|c|c|c|c|c|}
\hline \multicolumn{3}{|c|}{ PERTODO } & \multicolumn{2}{|l|}{1} \\
\hline $6^{a}$. & $3^{a}$ & $l^{a^{*}}$ & $2^{a}$ & 1 \\
\hline$i^{a}$ & $3^{a}$ & 5 . & 7 . $^{a *}$ & - \\
\hline $7^{\mathrm{a}}$ & $6^{a}$ & $x^{a}$ & - & $6 ?$ \\
\hline 4 ? & $2 ?$ & $6^{a}$ & $5^{a}$ & $7^{a}$. \\
\hline $2^{a}$ & 3. & $5^{a}$ & $4 \stackrel{a}{ }$ & $3^{a}$. \\
\hline $5^{a}$. & $4^{a}$. & $7 \stackrel{a}{.}$ & 2 ? & $4^{a}$ \\
\hline
\end{tabular}

Uni formização: $22 / 10 / 81$

Uniformização: $18 / 11 / 81$

Início : 29/10/81

Término

$: 09 / 12 / 81$

$\begin{array}{lll}\text { Início } & : & 25 / 11 / 81 \\ \text { Término } & : & 06 / 01 / 82\end{array}$

\section{PERTODO 3}

\begin{tabular}{|c|c|c|c|c|}
\hline $6^{a}$. & $4^{a}$. & 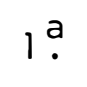 & $6^{a}$. & 1 \\
\hline $5^{a}$. & $3^{a}$ & 19 & $2^{a}$ & $1^{a}$ \\
\hline $7^{a}$ & $4 !$ & $7^{a}$ & $7^{a}$ & 4. \\
\hline $3^{a}$ & $3^{a}$ & $3^{a}$ & $5^{a}$. & 4. \\
\hline- & 3. & $2^{a}$ & $5^{a}$. & $6^{a}$. \\
\hline $5^{a}$. & - & $2 \stackrel{a}{.}$ & $7 \stackrel{a}{.}$ & $6^{a}$ \\
\hline
\end{tabular}

Uni formi zação: $16 / 12 / 81$

Início : 23/12/81

Término: : 03/02/82
PERTODO 2

7 . $\quad 1^{a} \cdot 5^{a} \cdot 3^{a} \cdot 4^{a}$

6. $\quad 3$ ? $\quad 2^{a} 7^{a} \cdot 1^{a}$

1. $\quad 2^{a} \quad 6^{a}$. $2^{a}$. $1^{a}$

5. $\quad 6^{a} \cdot 4^{a} \cdot \quad 7 \stackrel{a}{*} \quad 7$.

3. $\quad 5^{a} \quad 4^{a} \quad 3^{a} \cdot-$

2. $\quad 5^{a}$. $6^{a} 4^{a}$

* 1. e 7 . corresponde as idades de crescimento em semanas, ou seja, de 7 a 49 dias. 
Quadro 2 - Precipitação pluviométrica mm/dia duranté o período experimental

\section{DIAS/MESES}

Outubro $81 \quad$ Novembro 81 Dezembro 81 Janeiro 82 Fevereiro 82 Março 82

\begin{tabular}{|c|c|c|c|c|c|c|c|c|c|c|c|}
\hline Dias & $\mathrm{mm}$ & Dias & $\mathrm{mm}$ & Dias & $\mathrm{mm}$ & Dias & $\mathrm{mm}$ & Dias & $\mathrm{mm}$ & Dias & $\mathrm{mm}$ \\
\hline 03 & 4,7 & 01 & 0,7 & 01 & 39,1 & 01 & 29,1 & 01 & 20,2 & 01 & 9,9 \\
\hline 05 & 12,1 & 02 & 1,0 & 02 & 0,1 & 02 & 4,0 & 02 & 0,3 & 09 & 8,1 \\
\hline 06 & 14,1 & 03 & 14,0 & 04 & 25,0 & 07 & 50,0 & 04 & 43,0 & 10 & 8,9 \\
\hline 07 & 9,5 & 04 & 1,4 & 05 & 35,8 & 08 & 62,8 & 05 & 11,5 & 11 & 38,1 \\
\hline 10 & 3,5 & 07 & 1,8 & 06 & 5,4 & 09 & 7,1 & 06 & 8,0 & 14 & 10,8 \\
\hline 12 & 0,6 & 08 & 28,9 & 07 & 19,0 & 10 & 37,2 & 07 & 44,9 & 16 & 5,7 \\
\hline 15 & 19,5 & 09 & 50,1 & 08 & 19,0 & 11 & 20,3 & 16 & 6,7 & 17 & 1,3 \\
\hline 19 & $56 ; 8$ & 16 & 0,9 & 09 & 19,0 & 12 & 0,4 & 17 & 1,0 & 18 & 1,0 \\
\hline 26 & 22,3 & 18 & 26,0 & 13 & 19,1 & 20 & 2,8 & 18 & 1,2 & 21 & 5,4 \\
\hline 27 & 32,0 & 19 & 0,7 & 18 & 2,3 & 22 & 26,3 & $1-$ & 7,8 & 22 & 9,5 \\
\hline 28 & 4,7 & 20 & 10,0 & 24 & 2,0 & 23 & 0,8 & 23 & 2,4 & 25 & 26,9 \\
\hline 29 & 48,0 & 30 & 31,3 & 25 & 23,6 & 26 & 3,5 & 24 & 53,2 & 29 & 3,6 \\
\hline \multirow[t]{4}{*}{30} & 3,4 & & & 28 & 1,0 & 27 & 4,0 & 25 & 21,6 & 30 & 3,1 \\
\hline & & & & & & 28 & 9,0 & & & & \\
\hline & & & & & & 29 & 1,7 & & & & \\
\hline & & & & & & 31 & 0,2 & & & & \\
\hline
\end{tabular}

FONTE: Departamento de Agrometeorologia da ESALQ-USP. 
Em cada período, os tratamentos constaram de 7 idades de corte, variando de 7 a 49 dias.

Utilizou-se o delineamento inteiramente casualizado, constando de 4 repetições, sendo que cada parcela ocupou uma àrea de $4 \mathrm{~m}^{2}$. Obedeceu-se aos seguintes esquemas de análises de variāncias:

a) Produção de matéria seca dentro de cada período

\begin{tabular}{lc} 
CV & GL \\
\hline Idades & 6 \\
Residuo & 21 \\
\hline Total & 27 \\
\hline
\end{tabular}

b) Vigor da rebrota, \% de perfilhos decapitados e número total de perfilhos para três idades $(14,28$ e 42 dias)

\begin{tabular}{lc} 
CV & $G L$ \\
\hline Idades & 2 \\
Residuo & 9 \\
\hline Total & 11 \\
\hline
\end{tabular}

Para uma comparação entre os períodos efetuouse análise conjunta, obedecendo o proposto por BoX (1954), para as variáveis focalizadas. Produção de matēria seca, \% de perfilhos decapitados, nümero total de perfilhos e vigor da rebro- 
ta, obedecendo aos seguintes esquemas de anälises de variâncias:

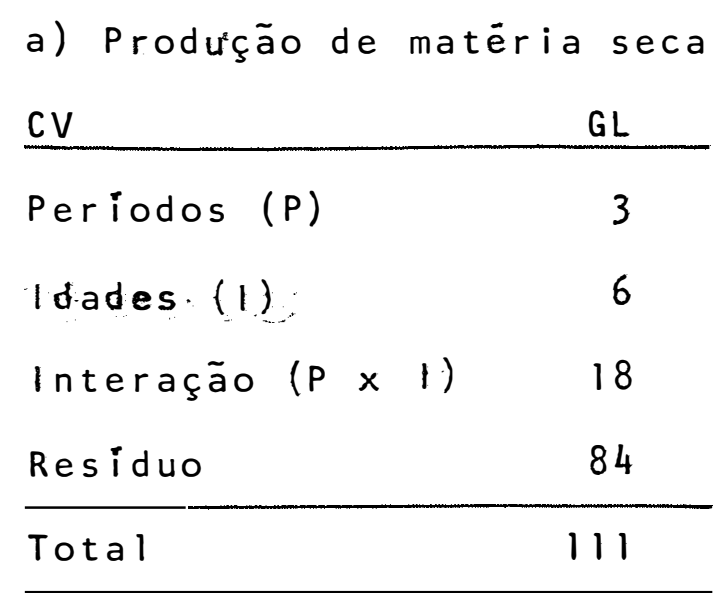

b) \% de perfilhos decapitados, nümero total de perfilhos e vigor da rebrota:

\begin{tabular}{lc} 
CV & $G L$ \\
\hline Periodos $(P)$ & 3 \\
Idades $(1)$ & 2 \\
Interação $(P \times 1)$ & 6 \\
Residuo & 36 \\
\hline Total & 47 \\
\hline
\end{tabular}

No dia $22 / 10 / 1981$ o experimento (todos os períodos) sofreu o corte de uniformização, a uma altura de 10 a $15 \mathrm{~cm}$ acima do nível do solo, essa altura foi também obedeci da durante a condução do experimento. Uma semana após a unifor mização iniciou-se a avaliação no primeiro periodo (correspondente ao crescimento do mês de novembrol e os demais cresceram livres. Na quarta semana (28 dias) de avaliação do período correspon- 
dente a novembro, os demais foram cortados e 7 dias apōs iniciou-se a avaliação do segundo período (mês de dezembro) e, assim, sucessivamente, nos demais períodos até o tērmino da avaliação (03/03/82). Com isso, a gramínea teve a mesma idade cronológica dentro de cada período de avaliação. o esquema de avaliação e idade da gramínea é dado no Quadro 3 .

Quadro 3 - Esquema do cronograma das frequências e ëpocas de cortes

PERTODO I

\begin{tabular}{ccc}
\hline Semana & Data & Idade \\
\hline- & $22 / 10 / 81$ & Uniformiz. \\
$1^{a}$ & $29 / 10 / 81$ & 7 dias \\
$2^{a}$ & $04 / 11 / 81$ & 14 dias \\
$3^{a}$ & $11 / 11 / 81$ & 21 dias \\
$4^{a}$ & $18 / 11 / 81$ & 28 dias \\
$5^{a}$ & $25 / 11 / 81$ & 35 dias \\
$6^{a}$ & $02 / 12 / 81$ & 42 dias \\
$7^{a}$ & $09 / 12 / 81$ & 49 dias \\
\hline
\end{tabular}

PERTODO 2

\begin{tabular}{ccc}
\hline Semana & Data & Idade \\
\hline- & $22 / 10 / 81$ & Uniformiz. \\
& & \\
& & \\
$4^{a}$ & & \\
$1^{a}$ & $18 / 11 / 81$ & Uniformiz. \\
$2^{a}$ & $25 / 11 / 81$ & 7 dias \\
$3^{a}$ & $02 / 12 / 81$ & 14 dias \\
$4^{a}$ & $09 / 12 / 81$ & 21 dias \\
$5^{a}$ & $16 / 12 / 81$ & 28 dias \\
$6^{a}$ & $23 / 12 / 81$ & 35 dias \\
$7^{a}$ & $30 / 12 / 81$ & 42 dias \\
\hline
\end{tabular}

$(\operatorname{cont}$. 
(cont.)

\begin{tabular}{ccc}
\multicolumn{3}{c}{ PERTODO 3} \\
\hline Semana & Data & Idade \\
\hline$-\quad 22 / 10 / 81$ & Uniformiz.
\end{tabular}

\begin{tabular}{ccc}
\multicolumn{3}{c}{ PERTODO 4} \\
\hline Semana & Data & Idade \\
\hline- & 22/10/81 Uniformiz.
\end{tabular}

4. $\quad 18 / 11 / 81 \quad$ Uniformiz.

$4^{\mathrm{a}}$

18/11/81 Uniformiz.

$\begin{array}{llc}4{ }^{a} & 16 / 12 / 81 & \text { Uniformiz. } \\ 1 . & 23 / 12 / 81 & 7 \text { dias } \\ 2^{a} \cdot & 30 / 12 / 81 & 14 \text { dias } \\ 3{ }^{a} & 06 / 01 / 82 & 21 \text { dias } \\ 4{ }^{a} & 13 / 01 / 82 & 28 \text { dias } \\ 5{ }^{a} & 20 / 01 / 82 & 35 \text { dias } \\ 6 . & 27 / 01 / 82 & 42 \text { dias } \\ 7^{a} & 03 / 02 / 82 & 49 \text { dias }\end{array}$

4. $\quad 16 / 12 / 81$ Uniformiz.

4. 13/01/82 Uniformiz.

1. $20 / 01 / 827$ dias

2. 27/01/82 14 dias

3. $\quad 03 / 02 / 82 \quad 21$ dias

4. $\quad 10 / 02 / 82 \quad 28$ dias

5. $\quad 17 / 02 / 8235$ dias

6. 24/02/82 42 dias

7. $03 / 03 / 8249$ dias 
Apōs o corte de uniformização, o material ceifado era retirado da ārea e procedia-se a adubação na base de $80 \mathrm{~kg} \mathrm{~N}, 20 \mathrm{~kg} \mathrm{P}_{2} \mathrm{O}_{5}$ e $90 \mathrm{~kg} \mathrm{~K} \mathrm{~K}_{2} \mathrm{O}$, respectivamente, na forma de nitrato de amōnea, superfosfato simples e cloreto de potássio.

Para efetuar os cortes de avaliações, usou-se um quadrado de ferro, com ärea ūti l de $1 \mathrm{~m}^{2}$. Esse dispositivo continha as touceiras de capim de duas linhas. Por ocasião dos cortes, eliminavam-se as bordaduras e registrava-se a produção de forragem verde do material contido dentro do quadrado e tirava-se uma amostra que, apōs sofrer pré-secagem, até peso constante, a $65^{\circ} \mathrm{C}$ em estufa com ventilação forçada, era pesada. os pesos de forragem verde foram convertidos em peso de matéria seca em função do teor de matéria seca das amostras.

A ärea cortada $\left(1 \mathrm{~m}^{2}\right)$ para determinar a produção de matéria seca era marcada com estácas para possibilitar o estudo da taxa de eliminação de meristemas apicais e determinar o vigor da rebrota.

Com objetivo de determinar o rítmo e época de elongação do meristema apical, 24 horas após o corte, contavase o nümero de perfilhos que emitiam brotações oriundas do meristema apical. Isso possibilitou o cálculo da percentagem de eliminação do meristema apical. 
Para avaliar-se o efeito da idade da planta ao tempo do corte sobre o vigor da rebrota, fêz-se a medição da produção da matēria seca, após 14 dias de rebrota.

\section{Experimento 2}

Para verificar possiveis influencias da altura e frequencia de cortes sobre o peso do sistema radicular de Andropogon gayanus, foi conduzido um experimento em vasos ao ar livre junto ao Departamento de Zootecnia da ESALQ.

os vasos eram de concreto com $0.1257 \mathrm{~m}^{2}$ de area e capacidade aproximada de $50 \mathrm{~kg}$, os quais foram cheios de terra cuja anālise química revelou os seguintes resultados: $\mathrm{pH}=5,6$; $\%$ carbono $=2,07 ; \mathrm{P}=24 \mathrm{ppm} ; \mathrm{K}=281 \mathrm{ppm} ; \mathrm{Al}^{+++}=$Traços; $\mathrm{Ca}_{\mathrm{a}}=6,88 \mathrm{~m} . \mathrm{eq} / 100 \mathrm{~g} ; \mathrm{Mg}=3,84 \mathrm{~m} . \mathrm{eq} . / 100 \mathrm{~g}$.

No centro de cada vaso fêz-se um sulco e adubou-se com o correspondente a $120 \mathrm{~kg} \mathrm{P}_{2} 0_{5}$ e $60 \mathrm{~kg} \mathrm{~K}_{2} 0 / \mathrm{ha}$, sob a forma de superfosfato simples e cloreto de potássio, respectivamente. Após a adubação, procedeu-se o plantio das sementes da forrageira, que ocorreu em 20 de setembro de 1980. Após a germinação efetuou-se o desbaste deixando uma planta por vaso.

o delineamento experimental foi inteiramente casualizado em esquema fatorial $2 \times 2$ com 4 repetiçöes. Sendo es- 
tudada a interação de duas alturas de cortes $(5$ e $20 \mathrm{~cm}$ ) com duas frequências de cortes $(30$ e 45 dias $)$.

No dia $30 / 10 / 1981$, iniciou-se a condução do ex perimento, efetuando-se o corte de uniformização, obedecendo as alturas de cortes pré-estabelecidas. Apōs o corte, cada vaso re cebeu em cobertura a adubação correspondente a $80 \mathrm{~kg} \mathrm{~N}, \quad 20 \mathrm{~kg}$ $\mathrm{P}_{2} \mathrm{O}_{5}$ e $90 \mathrm{~kg} \mathrm{~K} \mathrm{~K}_{2} / \mathrm{ha}$, respectivamente, nas formas de nitrato de amônia,superfosfato simples e cloreto de potássio; adubação essa que repetiu-se após cada corte até o fim do experimento.

A produção da forrageira verde de cada vaso foi registrada e, após sofrer uma pré-secagem, a $65^{\circ} \mathrm{C}$, em estufa, com ventilação forçada, foi pesada. Os pesos de forragem verde foram convertidos em pesos de matēria seca em função dos seus respectivos teores de matēria seca.

Durante o transcorrer do experimento atè $01 / 04 / 82$, realizaram-se 3 cortes na frequência de 45 dias e 5 cortes na frequência de 30 dias. Apōs o ültimo corte, os vasos foram submersos, por 24 horas, em um tanque contendo ägua, para permitir a retirada da terra sem danificar as raízes. Transcorrido o tempo, as raizes foram lavadas em āgua corrente sobre uma bateria de peneiras e, em seguida, separadas do restante da planta. 0 sistema radicular foi colocado em estufa com ventilação forçada a $65^{\circ} \mathrm{C}$ atè peso constante. 


$$
\text { Procedeu-se apōs a secagem a determinação da }
$$
quantidade de matéria orgânica no sistema radicular. Para tanto, foi avaliado o conteūdo de cinzas no material através da incineração em mufla a $600^{\circ} \mathrm{C}$. Esse procedimento teve como finalidade eliminar possiveis erros devido à contaminação de terra nas raizes.

os dados obtidos foram analisados obedecendo ao seguinte esquema de anălise de variância:

\begin{tabular}{lc}
$C V$ & $G L$ \\
\hline Tratamentos & 3 \\
Residuo & 12 \\
\hline Total & 15 \\
\hline
\end{tabular}


4. RESUltadOS

4.1. Produção de matéria seca.

A produção de matéria seca (kg/ha) do Andropogon gayanus, diferiu significativamente entre os períodos e tra tamentos (idades) estudadas, porém, a interação periodos $\times$ tratamentos não foi significativa (Quadro 4). As produções dos períodos foram comparadas pelo teste de Tukey (Quadro 5), enquanto que as das idades foram estudadas através de regressão (Figu ra 1).

Os dados relativos à produção de matéria seca do capim Andropogon, resultantes da combinação dos períodos com as idades estudadas são apresentadas no Quadro 5, bem como, as médias dos periodos e das idades. Observa-se que houve diferenças significativas entre os períodos estudados. A melhor produção média de matéria seca foi obtida no periodo novembro 81 - 
janeiro 82, quando esta planta forrageira produziu cerca de $4100 \mathrm{~kg} M S / \mathrm{ha}$.

A produção média do período dezembro 81 - feve reiro 82 foi ao redor de $3.300 \mathrm{~kg}$ MS/ha e, significativamente inferior às mëdias obtidas nos demais períodos. Porém, a média obtida em janeiro-março $82(3.522 \mathrm{~kg} \mathrm{MS/ha)}$ foi semelhante a de :utubro-dezembro $81(3.890 \mathrm{~kg} \mathrm{MS/ha})$.

A produção de matéria seca da forrageira em função da idade durante os períodos estudados, ajusta-se a uma regressão linear com $R^{2}=97 \%$, que é representada na Figura 1 . Quadro 4 - Anālise da variância da produção de matéria seca do capim Andropogon

\begin{tabular}{|c|c|c|c|c|c|}
\hline Causa da v & vari ação & $\mathrm{GL}$ & $S Q$ & $Q M$ & $F$ \\
\hline Períodos ( & $(P)$ & 3 & 10774362,01 & 3591454,00 & $6,25^{*}$ \\
\hline Idades (1) & & $(6)$ & $(752887130,75)$ & - & \\
\hline Efeito 1 & linear & 1 & 737040627,06 & 737040627,06 & $1281,63^{\star *}$ \\
\hline Efeito $q$ & quadrätico & 1 & 10441704,90 & 10441704,90 & $18,21^{* *}$ \\
\hline Desvio d & da regressäo & 4 & 5374798,79 & 1343699,70 & $2,34^{\text {ns }}$ \\
\hline Interação & $(P \times 1)$ & 18 & 15777768,01 & 876542,67 & $1 ; 52^{\text {ns }}$ \\
\hline Residuo & & 84 & 48306904,05 & 575082,19 & \\
\hline Total & & 111 & 827746165,81 & - & \\
\hline
\end{tabular}




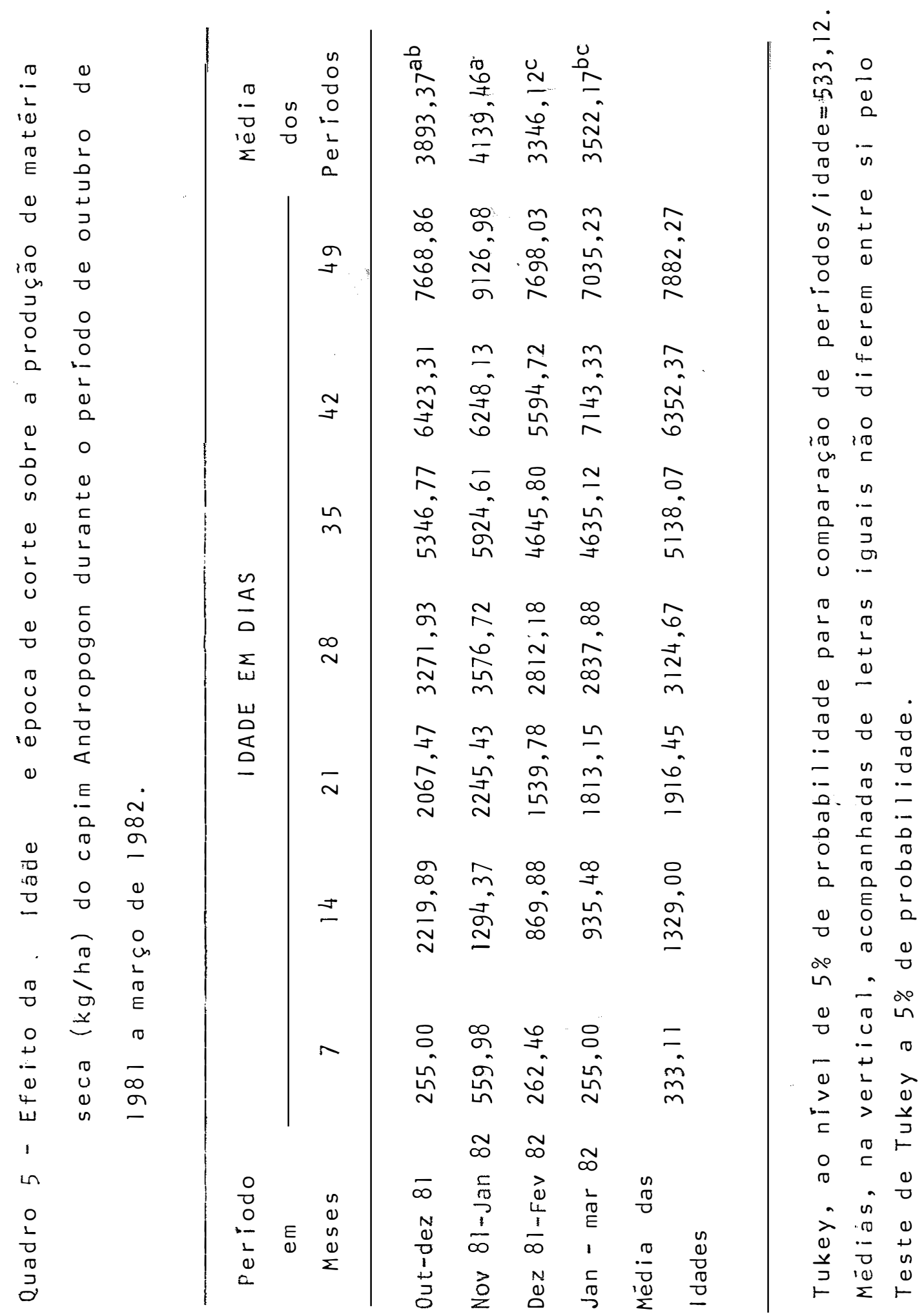




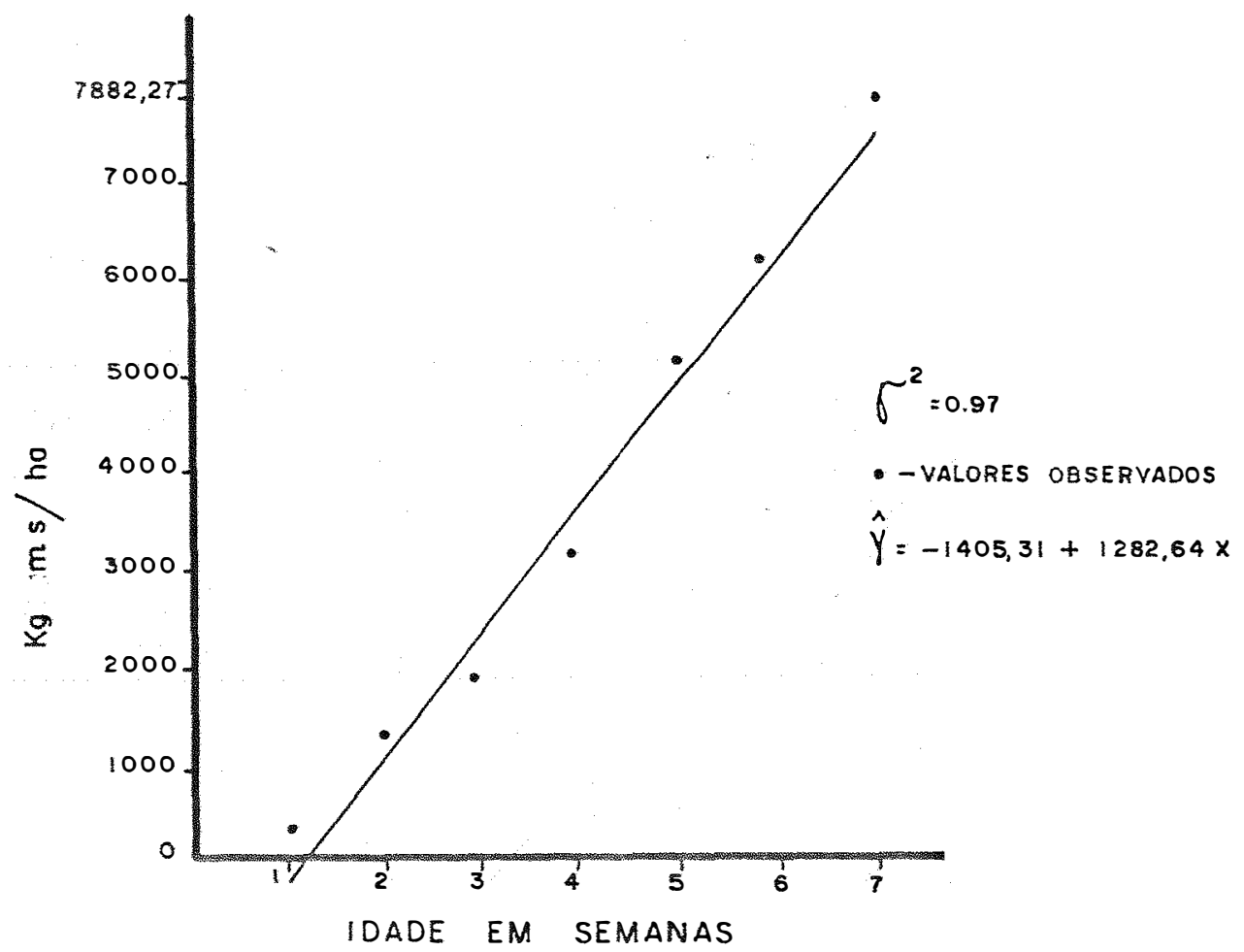

Figura 1 - Efeito da idade sobre a produção de matéria seca do capim Andropogon colhido no periodo de outubro de 1981 a março de 1982 . 
4.2. Variação no nümero total de perfilhos para idades de

o nümero total de perfilhos do capim Andropogon foi afetado pelos períodos de corte, pela maturidade e pela interação desses dois fatores como mostra o Quadro 6. Como a interação foi significativa a análise da variância já está apre sentada em termos de decomposição de períodos dentro de tratamentos.

o nūmero total de perfilhos nesta planta forra geira durante o período de outubro-dezembro de 1981 foi signifi cativamente superior quando comparado com aqueles encontrados nos demais periodos (Quadro 7). Assim, aos 14 dias de crescimen to o nümero de perfilhos para esse período de crescimento era de $1965 / m^{2}$ enquanto esse valor diminuiu significativamente para 1369 perfilhos/m² quando o crescimento do capim Andropogon foi iniciado no mês de novembro. 0 perfilhamento do capim Andropogon decresceu ainda mais, tendendo para uma estabilização ao redor de 550 perfilhos $/ \mathrm{m}^{2}$, quando a planta iniciou o crescimento em dezembro ou janeiro. Quando o tempo de crescimento desta planta forrageira foi maior do que 28 dias, o perfilhamento foi maior durante o período de outubro a dezembro enquanto os demais períodos não diferiram entre sí. 0 nümero de perfilhos/m² diminuiu entre 30 a $45 \%$ e 39 a $59 \%$ quando se comparou o perfilhamento do período outubro-dezembro com os demais períodos para os crescimentos de 28 e 42 dias, respectivamente. 
Quadro 6 - Anālise da variância do nümero total de perfilhos do capim Andropogon no período outubro 81 a março 82

\begin{tabular}{lcccc} 
Causa de variação & GL & SQ & QM & $F$ \\
Idade (1) & 2 & 619670,37 & 309835,19 & $15,03^{* *}$ \\
Periodos/ldade 1 & 3 & 5636505,50 & 1878835,19 & $91,13^{* *}$ \\
Periodos/Idade 2 & 3 & 821086,69 & 273695,56 & $13,28^{* *}$ \\
Períodos/Idade 3 & 3 & 15711115,69 & 523705,23 & $25,0^{* *}$ \\
Residuo & 36 & 742181,00 & 20616,14 & \\
\hline Total & 47 & 9390559,25 & &
\end{tabular}

Quadro 7 - Efeito da idade e da época de corte sobre o nūmero total de perfilhos do capim Andropogon por $\mathrm{m}^{2}$, durante o período de outubro 81 a março 82

\begin{tabular}{lccc}
\hline $\begin{array}{c}\text { Periodos } \\
\text { em } \\
\text { Meses }\end{array}$ & 14 & IDADE EM DIAS & \\
\hline Out - dez 81 & $1965,5^{a} 0^{a}$ & 28 & 42 \\
Nov 81-jan 82 & $1369,50^{b}$ & $1346,75^{a}$ & $1347,25^{a}$ \\
Dez 81-fev 82 & $541,75^{c}$ & $955,25^{b}$ & $557,75^{b}$ \\
Jan - mar 82 & $574,25^{c}$ & $753,5^{b}$ & $603,75^{b}$ \\
\hline
\end{tabular}

Tukey, ao nível de $1 \%$ de probabilidade para comparação períodos/ idades $\quad=340,29$.

Na mesma coluna, médias acompanhadas de letras iguais não diferem entre si pelo Teste de Tukey a $1 \%$ de probabilidade. 
4.3. Porcentagem de eliminação de meristemas apicais.

A anālise de variância, para a porcentagem de eliminação de meristemas apicais (Quadro 8) revela que houve efeito significativo dos períodos de corte, das idades, e da interação períodos $x$ tratamentos sobre a porcentagem de eliminação dos meristemas apicais do capim Andropogon. Como a interação foi significativa a anālise de variância já está apresentada em termos de decomposição de períodos dentro de tratamentos.

Através do Quadro 9 observa-se que a porcentagem de eliminação dos meristemas apicais é mais elevada para o período de janeiro-março, independentemente da idade de crescimento da planta.

A eliminação dos meristemas apicais das plantas que iniciaram o crescimento entre outubro e dezembro, é baixa e ao redor de, no máximo, $1 \%$ quando o estádio de crescimento da planta é de 14 ou 28 dias. Entretanto, para as plantas que cresceram por 42 dias, a porcentagem de eliminação de meristemas apicais aumenta de $4,15 \%$ para $9,04 \%$ quando as plantas iniciaram o crescimento no período de outubro-dezembro e dezembro-fevereiro, respectivamente. Para as plantas que cresceram por 42 dias a porcentagem de meristemas apicais eliminados aumentou significativmaente para cada período de corte estudado. . 
Quadro 8 - Anälise da variância da porcentagem de eliminação de meristemas apicais do capim Andropogon, cortado entre $10-15 \mathrm{~cm}$ do nivel do solo

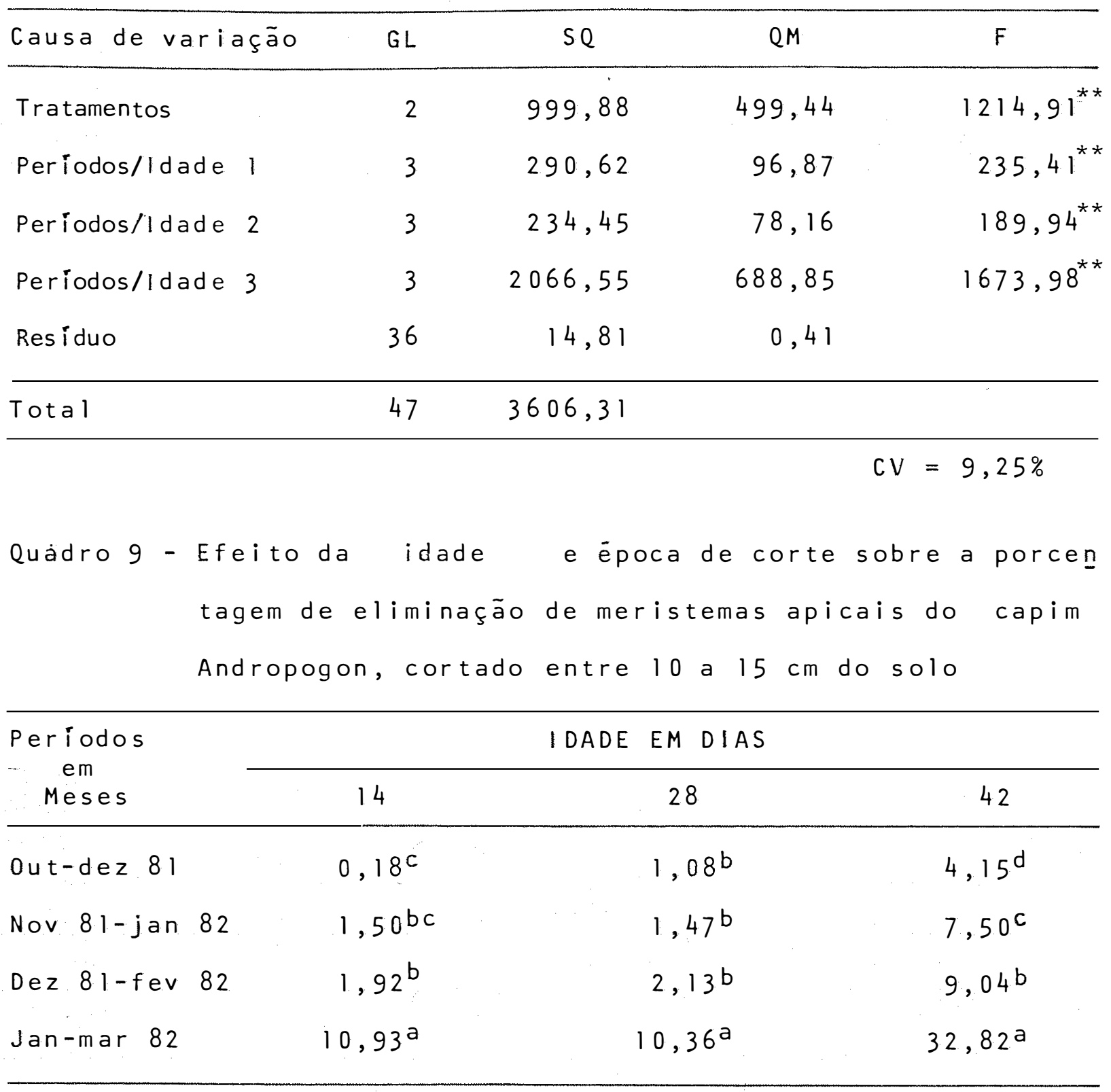

Tukey, ao nivel de $1 \%$ de probabilidade para comparação de períodos / idades $=1,52$.

Na mesma coluna, mëdias acompanhadas de letras iguais não diferem entre si pelo Teste de Tukey a $1 \%$ de probabilidade. 
Independentemente da idade da planta, a eliminação de meristemas apicais foi sempre mais elevada para o período de crescimento iniciado em janeiro-março, sendo que a maior porcentagem de eliminação de meristemas apicais, cerca de $33 \%$, ocorreu neste período nas plantas que vegetaram por 42 dias.

4. 4. Vigor da rebrota.

A análise de variância para verificar o efeito da idade e período de corte sobre o vigor da rebrota é apresentada no Quadro 10 , sendo que a análise conjunta e o desdobramento dos efeitos da interação períodos $x$ idades não foram efetuados porque a discrepância entre os quadrados médios das análises individuais foi maior do que aquela recomendado por $\operatorname{BOX}(1954)$.

A capacidade de rebrota do capim Andropogon gayanus avaliada apōs 14 dias do corte é apresentada no Quadro 11 , em que se nota maior vigor da rebrota independentemente do periodo de corte para as plantas que cresceram por 28 dias. Por outro lado, não se observou diferença para o vigor da rebrota entre as plantas que iniciaram o crescimento em outubronovembro e vegetaram por 14 ou 28 dias. Para as plantas que vegetaram por 28 dias a produção da rebrota variou entre cerca de 1100 e $1800 \mathrm{~kg}$ MS/ha durante o periodo experimental, enquan- 
Quadro 10 - Anālise da variância para o vigor da rebrota do capim Andropogon

\begin{tabular}{lrrrrr}
\hline Causa da & \multirow{2}{*}{ Variação } & QL & \multicolumn{4}{c}{ DOS PERTODOS } \\
\cline { 2 - 5 } & & Out-dez 81 & Nov81-Jan82 & Dez81-Fev82 & Jan-Mar 82 \\
\hline Idade &. & $1392796,77 * *$ & $299802,19^{*}$ & $600933,62 * *$ & $870746,50 * *$ \\
Residuo & 88037,64 & 38183,67 & 15819,36 & 69623,65 \\
\hline & CV $=24,68$ & CV $=21,38$ & CV $=16,32$ & CV $=27,68$
\end{tabular}

Quadroll Efeito da idade e época de corte sobre o vigor da rebrota (kg MS/ha) do capim Andropogon, cortado entre 10 e $15 \mathrm{~cm}$ do solo

\begin{tabular}{lcccc}
\hline $\begin{array}{c}\text { Periodos } \\
\text { em } \\
\text { Meses }\end{array}$ & 14 & IDADES EM DIAS & $\begin{array}{c}\text { Nivel } \\
\text { de }\end{array}$ \\
\cline { 2 - 4 } Out - dez 81 & $1050,75^{\mathrm{ab}}$ & $1853,09^{\mathrm{a}}$ & $702,39^{\mathrm{b}}$ & $\Delta 1 \%=805,57$ \\
Nov $81-$ jan 82 & $974,63^{\mathrm{ab}}$ & $1152,23^{\mathrm{a}}$ & $614,88^{\mathrm{b}}$ & $\Delta 5 \%=385,93$ \\
Dez $81-$ fev 82 & $752,48^{\mathrm{b}}$ & $1166,96^{\mathrm{a}}$ & $392,40^{\mathrm{c}}$ & $\Delta 1 \%=341,48$ \\
Jan - mar 82 & $474,85^{\mathrm{b}}$ & $1407,05^{\mathrm{a}}$ & $977,18 \mathrm{ab}$ & $\Delta 1 \%=716,39$ \\
\hline
\end{tabular}

Na mesma linha, mëdias acompanhadas de letras iguais não diferem entre si pelo Teste de Tukey a $5 \%$ e $1 \%$ de probabilidade. 
to esses valores variaram entre 474 e $1050 \mathrm{~kg}$ MS/ha para as p.lantas com $14^{\circ}$ dias de crescimento e entre 392 e 977 para aque las que cresceram por 42 dias.

o vigor da rebrota para as plantas que cresceram por 14 ou 42 dias foi semelhante para todos os periodos de corte, exceto para o de dezembro-fevereiro. Nesta ēpoca o vigor da rebrota para as plantas com 42 dias foi a menor observada durante o periodo experimental, ou seja, cerca de $392 \mathrm{~kg}$ MS/ha quando, neste periodo, obteve-se 1166 e 752 kg MS/ha para a rebrota das plantas que cresceram por 28 e 14 dias, respectivamente.

\subsection{Altura e frequência de cortes $x$ sistema radicular}

A anālise de variància com a finalidade de ve rificar o efeito da interação alturas x frequências de cortes, sobre a produção de matēria seca da parte aérea e peso total da matéria orgânica do sistema radicular do capim Andropogon è apresentada no Quadro 12. Observa-se que a produção de matē ria seca da parte aérea foi afetada pela frequência de corte mas não pela altura ou pela interação desses dois fatores. Por outro lado, o desenvolvimento do sistema radicular avaliado pela produção de matēria orgânica, foi afetado pela altura e frequência de corte bem como pela interação desses fatores. 


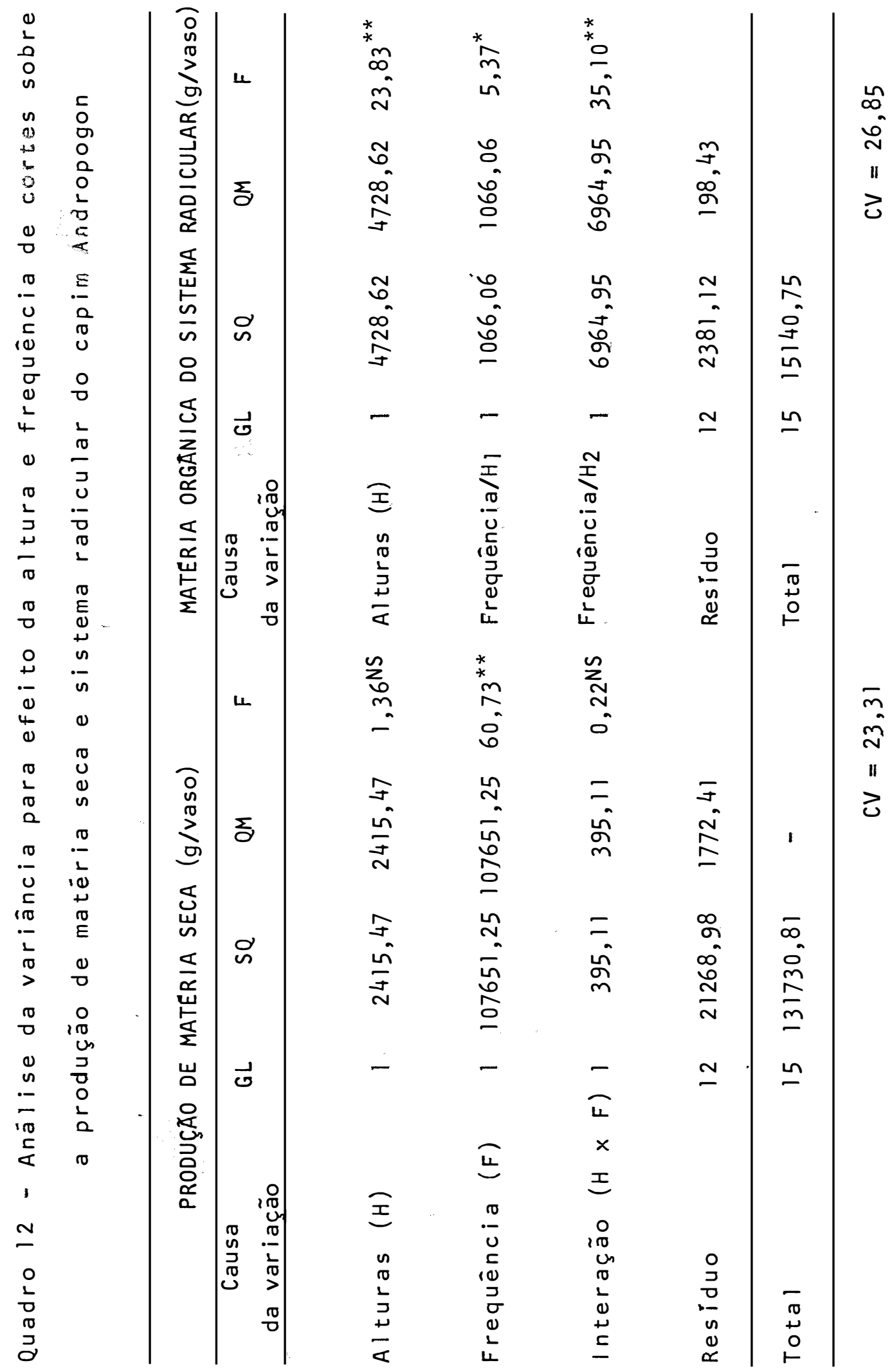


0 efeito das alturas $(H)=5 \mathrm{~cm} \mathrm{e} H_{2}=20 \mathrm{~cm} \mathrm{do}$ solo) e das frequências de cortes $\left(F_{i}=30 \mathrm{dias}\right.$ e $F_{2}=45 \mathrm{dias}$ de intervalo entre cortes) foi avaliado em termos de produção de matéria seca da parte aérea e de produção de matéria orgâni ca do sistema radicular, que são apresentados no Quadro 13.

Quadro 13 - Efeito da altura e frequência de cortes sobre a produção de matēria seca da parte aérea (g/vaso) e peso total de matéria orgānica do sistema radicu $\operatorname{lar}$ (g/vaso) do capim Andropogon

\begin{tabular}{|c|c|c|}
\hline Tratamentos & $\begin{array}{c}\text { Matēria seca da } \\
\text { parte aērea }\end{array}$ & $\begin{array}{c}\text { Matēria orgânica do } \\
\text { sistema radicular }\end{array}$ \\
\hline $\mathrm{H}_{\mid} \mathrm{Fl}_{\mathrm{I}}$ & 91,23 & 23,72 \\
\hline $\mathrm{H}_{2} \mathrm{Fl}_{\mathrm{l}}$ & 105,87 & 40,14 \\
\hline $\mathrm{H}_{1} \mathrm{~F}_{2}$ & 245,35 & 46,81 \\
\hline $\mathrm{H}_{2} \mathrm{~F}_{2}$ & 279,86 & 92,16 \\
\hline
\end{tabular}

A produção de matéria seca da parte aérea do capim Andropogon foi reduzida pelo efeito da frequéncia de corte em $62,17 \%$ quando a frequência de corte passou de 45 dias de intervalo entre cortes para 30 dias. 0 s resultados acusam tendências indicando que a medida que a altura de corte passa de 5 para $20 \mathrm{~cm}$ do solo a produção de matéria seca aumenta. 
A produção de matéria orgânica do sistema radicular diminuiu acentuadamente à medida que cortes mais frequentes $(30 \mathrm{dias})$ e mais baixos $(5 \mathrm{~cm})$ foram efetuados. Observa-se que os prejuízos para o sistema radicular são menores à medida que se aumentava o intervalo ou que se elevava a altura dos cortes. Assim, quando a frequência de corte pas sou de 30 para 45 dias na altura de $5 \mathrm{~cm}$ o desenvolvimento do sistema radicular quase que duplicou. 0 desenvolvimento do sistema radicular do capim Andropogon foi, no entanto, significativamente maior quando a frequência e altura de cortes foi de 45 dias e $20 \mathrm{~cm}$, respectivamente. Através dessa observação de frequência e altura de corte obteve-se um desenvolvi mento do sistema radicular cerca de quatro vezes superior àquele observado quando o capim Andropogon era submetido a cortes cada $30 \mathrm{dias}$ e a $5 \mathrm{~cm}$ do solo. 
5. DISCUSSAO

A produção de matéria seca do capim Andropogon no período novembro 81 - janeiro 82 foi superiór às encontradas nos demais períodos avaliados. Nesse período houve uma redução sensível no número total de perfilhos da planta forrageira com o aumento da idade. Embora havendo redução significativa na densidade de perfilhos, a produção de matéria seca aumentou significativamente. Mostrando com isto que, após o es tabelecimento da planta forrageira, o mais importante é o peso dos perfilhos e não o número. Aos 49 dias de idade foi observa do o menor número de perfilhos $\left(558 / \mathrm{m}^{2}\right)$, entretanto, a planta forrageira atingiu elevada produção $(9126 \mathrm{~kg} \mathrm{MS} / \mathrm{ha})$. Tal fato pode ser explicado pela maior disponibilidade dos fatores de crescimento, como umidade e calor, observado. nesse período, contribuindo assim, para a gramínea expressar o seu potencial produtivo. Comportamento similar foi encontrado por 
PEDREIRA (1975), comparando variedades de Brachiarias, variedades de Panicum, Hyparrhenia rufa e Setaria anceps. oscilações na produção de matéria seca entre os períodos estuda dos, segundo CORSI $\left(1982^{*}\right)$ pode ser atribuida entre outros fa tores, à variação na quantidade de graus dia, o que foi obser vado em trabalho realizado com o capim de rhodes.

o potencial produtivo de Andropogon gayanus, em função das idades, variou de 1332 a 31529 kg MS/ha, aos 7 e 49 dias, respectivamente, durante a estação de crescimento, ou seja, de outubro a março. Neste período a produtividade do capim Andropogon guarda relação direta com a idade $\left(R^{2}=97 \%\right)$.

Sem levar em consideração a qualidade do capim Andropogon, cujos estudos estão em andamento, acredita-se que - manejo desta planta forrageira deve ser efetuado com intervalo entre cortes ao redor de 45 dias e a uma altura de $20 \mathrm{~cm}$ do solo, como indicam os resultados do experimento conduzido nos vasos. Cortes efetuados a altura de $5 \mathrm{~cm}$ comparados com os de $20 \mathrm{~cm}$ não diferiram quanto a-produção de matéria seca da parte aérea, entretanto, observa-se que a produção do sistema radicular foi diminuida drasticamente, entre $49,3 \%$ e $59,5 \%$, quando os cortes eram baixos. Esse fato comprova que o sistema radicular é a parte da planta forrageira mais sensivel ao * CORSI, M. 1982. Comunicação pessoal. 
mal manejo, sendo que os prejuizos do manejo incorreto refle tem-se, posteriormenté, na parte aérea como demonstram os trabalhos de WHYTE (1973). Este autor explica que os efeitos da altura e frequència de cortes são manifestados, primeiramente, no sistema radicular da planta forrageira porque as substâncias armazenadas nas raízes são usadas como fonte de energia para promover os primeiros crescimentos após a elimi nação da parte aérea. Por outro lado, cortes que eliminam completamente a parte aérea e atrasa o desenvolvimento da ärea foliar, dependem exclusivamente de reservas orgânicas situadas abaixo ou acima do nivel do solo para estabelecer novo crescimento, como se pode concluir do trabalho de BOTREL (1980). Os produtos de fotossintese no inicio da rebrota são utilizados para expansão de novas folhas em detrimento ao crescimento do sistema radicular. Desse modo, explica-se a afirmação de YOUNGNER (1972) que concluiu que a eliminação de mais do que $40 \%$ da parte aérea paraliza o desenvol vimento do sistema radicular das gramíneas forrageiras.

Cortes baixos $(5 \mathrm{~cm})$ efetuados com intervalos a cada 45 dias prejudicam menos o desenvolvimento do sistema radicular quando comparado com os cortes baixos e frequentes (a cada $30 \mathrm{dias}$ ), mas a combinação de corte alto $(20 \mathrm{~cm}$ ) e a cada 45 dias possibilitaram o melhor desenvolvimento do sistema radicular e produção de matēria seca da parte aērea. 
O desenvolvimento do sistema radicular nas plan tas forrageiras reveste-se de importancia pela disponibilidade de ägua e de minerais explorada em maior volume de terra. Em solos férteis e com umidade disponivel o desenvolvimento do sistema radicular não é tão limitante para a nutrição de planta como em condições onde esses fatores de crescimento são mais escassos. Assim, a difusão de nutrientes na solução do solo que representa entre 70 a $90 \%$ do potāssio e do fósforo ab sorvido pela planta (COREY, 1974) depende da disponibilidade de ăgua e da distância entre a fonte de nutriente e o sistema radicular. Sistema radicular vigoroso tende a reduzir o espaço até a fonte de nutrientes e pode estar sempre em contacto com ägua disponível em camadas mais profundas do solo.

o perfilhamento das gramíneas è um reflexo de atores de crescimento como disponibilidade de nutrientes, principalmente de nitrogènio (WILSON e HAYDOCK, 1971), de luminosidade ao nível da coroa das gramíneas e de temperatura (LANGER, 1963 e VARTHA, 1973). De uma maneira geral, pode-se afirmar que o perfilhamento depende dos produtos da fotossíntese. Assim, quanto mais favorável forem as condições para a fotossintese, maior serā o perfilhamento (MILTHORPE e MOORBY, 1975). Desse modo, pode-se explicar o ocorrido com o capim An dropogon no inicio do periodo de crescimento das planta forra geiras, ou seja, de outubro a dezembro, quando houve maior per filhamento comparado com aquele de janeiro-março. Este compor- 
tamento do capim Andropogon ē semelhante ao determinado por PEDREIRA (1975) com o capim colonião. Por outro lado, deve-se observar que as condições climäticas predominantes para o periodo de novembro-janeiro e de dezembro-fevereiro são consi deradas ainda muito favoráveis ao perfilhamento, mas este foi signnificativamente diminuído em relação àquele observado para o periodo de outubro-dezembro. Este fato não pode ser atribuído a falta de nutrientes uma vez que após cada corte de uniformização as plantas foram adubadas convenientemente. Também essa redução no perfilhamento, talvez não se deva à decapitação de perfilhos que foi muito baixa e ao redor de $2 \%$ até o período de dezembro-fevereiro (Quadro 9). Além disso, mesmo quando a porcentagem de eliminação de perfilho foi significativamente mais elevada, como ocorreu para o período de janeiro-março, não se observou diferenças significativas para o nümero de perfilhos entre os períodos de novembro-janeiro até janeiro-março, compreendendo três períodos de corte estudados. Somente as plantas com 14 dias de idade apresentaram maior per filhamento no periodo de novembro-janeiro em relação aos de dezembro-fevereiro e janeiro-março (Quadro 9).

o menor perfilhamento do capim Andropogon, a cada periodo de corte estudado, pode ser atribuído ao fotoperíodo, uma vez que o nümero de perfilhos decapitados aumentou no período de janeiro-março. Neste caso, perfilhos vegetativos cujos meristemas apicais não foram eliminados rebrotam rapida- 
mente, provocando sombreamento ao nivel da coroa das plantas e, consequentemente, inibindo o desenvolvimento de novos perfilhos. Este fato explica os resultados apresentados no Quadro 9 , em que se nota uma estacionalidade marcante no nümero de perfilhos, isto é, o maior perfilhamento ocorreu em outubro-dezembro.

TOMPSETT (1976) verificou que o capim Andropogon é uma planta de dias curtos e que o florescimento ocorre quando o comprimento do dia atinge 12 horas aumentando à medida que o dia torna-se mais curto. Este autor tambëm verificou que a $25^{\circ} \mathrm{C}$ o nümero de inflorescència aumentou. Estes fatos como sugerem BOOYSEN et alii(1963), explicam a baixadecapitação de perfilhos do capim Andropogon que foi ao redor de $2 \%$ até o período de dezembro-fevereiro para as plantas que vegetaram por 14 e 28 dias (Quadro 9). Somente no período final da estação de crescimento è que se eliminou cerca de $33 \%$ dos meristemas apicais. Este fato sugere que o capim Andropogon apresenta alongamento das hastes tardiamente, quando comparado com o capim colonião que aos 49 dias de crescimento, cerca de $43 \%$ dos perfilhos foram eliminados (GOMIDE et alii, 1979) e com o capim gordura, buffell e napier que tiveram $100 \%$ dos meristemas apicais eliminados ao redor de 60 dias de crescimento (NASCIMENTO, 1971; ANDRADE e GOMIDE, 1971). 0 alongamento tardío das hastes do capim Andropogon e, consequentemen- 
te, a baixa eliminação dos meristemas apicais pode favorecer a rebrota vigorosa dessa gramínea após o corte como sugere o trabalho de BOOYSEN et alii (1963).

A diminuição no nümero de perfilhos também pode, ser explicada pelo corte de uniformização muito frequente, isto è, a cada 28 dias, que foi imposta pela metodologia aplicada neste trabalho por falta de melhores informações (CENTRO INTERNACIONAL DE AGRICULTURA TROPICAL, 1978; GROF, 1981). COMO revelaram os resultados do experimento conduzido em vasos (Quadros 12 e 13 ) cortes efetuados com intervalos a cada 30 dias reduziram a produção de matéria seca em cerca de 62,2\% independentemente das alturas de cortes estudadas que foram de 5 e 20 cm do solo. Se esta hipōtese for aceita para explicar a redução no perfilhamento e produção de matéria seca do capim Andro pogon, pode-se sugerir pelos resultados apresentados nos Quadros 5,7 e 13 que esta planta forrageira é extremamente exigente a condições de manejo referentes à altura e frequência de cortes uma vez que cortes baixos $(5 \mathrm{~cm}$ ) e frequentes ( 30 dias), reduzem drasticamente o sistema radicular, a produção de matéria seca da parte aérea e o perfilhamento. Considerando as condições físicas e quimicas dos solos onde se conduziu os experimentos de campo e de vasos, pode-se sugerir que os efeitos prejudiciais do manejo incorreto sobre o capim Andropogon seriam mais severos em solos mais pobres física ou qui- 
micamente. Este fato deve ser enfatizado já que esta planta forrageira tem sido divulgada e recomendadá para solos pouco fērteis e ácidos. Os trabalhos do CENTRO INTERNACIONAL DE AGRICULTURA TROPICAL (1978) e GROF (1981) sugerem que o capim Andropogon vegeta adequadamente em condições de solos pouco férteis e ácidos, como os dos cerrados do Brasil Central, mas a literatura é pobre em relacionar esta propriedade da gramínea com as suas exigências em termos de manejo. Sugere-se, portanto, maior cautela na recomendação desta planta forrageira até que outros estudos esclareçam as suas exigências em termos de manejo e utilização nas condições do Brasil.

Considerando os resultados dos experimentos con duzidos pode se sugerir que a maior persistência do capim Andropogon deve ser obtida com cortes efetuados ao redor de 40 dias e acerca de $15 \mathrm{~cm}$ de altura. Colheitas efetuadas com maior frequência do que as sugeridas prejudicam seriamente a produtividade e persistência dessa gramínea sendo que a elevação da altura de corte pode, somente, retardar, mas não eliminar o efeito da frequência incorreta de corte. 
6. CONCLUSOES

Nas condições experimentais e de acordo com os resultados obtidos, pode-se concluir que:

1. A produtividade do capim Andropogon aumenta diretamente com a idade.

2. Cortes efetuados a cada 30 dias reduz drasticamente a produtividade de matēria seca da parte aérea, mas não se observou o mesmo efeito para a altura de corte que variou de 5 e $20 \mathrm{~cm}$.

3: 0 desenvolvimento do sistema radicular é prejudicado tanto pela frequência como pela altura de corte.

4. 0 capim Andropogon apresenta alongamento tardio das hastes. 
5. Trata-se de uma graminea extremamente exigente em relação ao manejo, fator que pode limitar o sucesso das recomendações para a utilização desta planta forrageira em condições de solos pouco férteis e ácidos.

6. A maior produtividade e persistência desta gramínea são obtidas através de cortes ao redor de 40 dias e a altura de cerca de $15 \mathrm{~cm}$.

7. Os resultados obtidos no experimento de campo podem ter sido influenciados pela elevada frequência dos cortes de uniformização ( 28 dias), visto que cortes frequentes e baixos parecem prejudicar o capim Andropogon como deter minado no experimento em vasos. 
7. LITERATURA CITADA

ALCANTARA, P.B. e G. BUFARAH. 1979. Plantas Foorageiras: gramineas e Zeguminosas. São Paulo, Ed. Nobel. 146p.

ANDRADE, J.F. e J.A. GOMIDE. 1971. Curva de crescimento e valor nutritivo de capim-elefante (Pennisetum purpureum, Schum). A-146 Taiwan. Revista Ceres, Viçosa, 18(100):431-447.

ARAOJO, J.C. e A.V.A. JACQUES. 1974. Influência do estádio de crescimento e da altura de corte sobre as reservas de gl cideos e nitrogênio total do cornichão (Lotus corniculatus). Revista da Sociedade Brasileira de Zootecnia, Viçosa, 3(2): $123-137$ 
ASARE, E.0. 1974. Drymatter yield, chimical composition and nutritive value of Buffel grass grown alone and in mixture with other tropical grasses and legumes. In: $12^{\text {th }}$ International Grassland Congress, Moscow, p.53-54.

BARBER, S.A. 1966. The role of root interceptation mass flow and diffusion in regulating the uptake of ions by plants from soil. Technical Report Series International Atomic Energy on Agriculture, Vienna, 65:39-45.

BOOYSEN, P.V.; N.M. TAITON E J.D. SCOTT, 1963. Shoot apex development in grasses and its importance in grassland management. Herbage Abstracts, Aberystwyth, 33(4):209-213.

BOX, G.E.P. 1954. Non-normality and tests on variances. Biometrica. Cambridge, $40: 318-335$.

BOTREL, M.A. 1980. Importância dos carboidratos de reserva e da preservação dos meristemas apicais na rebrota do capim jaraguá (Hyparrhenia rufa (Ness) Stapf). Viçosa, U.F.V., $41 \mathrm{p}$ (Tese de Mestrado).

BOGDAN, A.V. 1977. Tropical pastures and fodder plants. London, Longman. $475 p$. 
BOWDEN, B.N. 1963a. Studies on Andropogon gayanus Kunth.

1. The use of Andropogon gayanus in agriculture. Empire Journal of Experimental Agriculture, 0xford, 31:267-273.

BOWDEN, B.N. 1963b. The root distribution on Andropogon gayanus var. bisquamulatus. East African Agricultural and Forestry Journal, Nairobi, 28:157-159.

BROUGHAM, R.W. 1956. Effect of intensity of defoliation on regrowth of pasture. Australian Journal of Agricultural Research, Melbourne, $7(5): 377-387$.

BROWN, R.H. e R.E. BLASER. 1970. Soil moisture and temperature effects on growth and soluble carbohydrates of orchard grass (Dactylis glomerata). Crop Science, Madison, 10(3): $213-216$

CENTRO INTERNATIONAL DE AGRICULTURA TROPICAL. 1978. Programa de pastos tropicales. Informe Anual CIAT, Cali, 174 .

CENTRO INTERNACIONAL DE AGRICULTURA TROPICAL. 1979. Programa de pastos tropicales. Informe Anual CIAT, Cali; P. B $34-$ B 47 . 
CENTRO INTERNACIONAL DE AGRICULTURA TROPICAL. 1980. Programa de pastos tropicales. 'Informe Anual CIAT, Cali, p.69-87.

CORREA, L. de A. 1981. Efeito do intervalo de cortes sobre os teores de carboidratos de reserva, peso das raízes e pro dução de matéria seca do capim jaraguá (Hyparrhenia rufa (Ness) Stapf) apōs diferentes tempos de rebrota. Viçosa, U.F.V. 27p. (Tese de Mestrado).

COREY, R.B. 1974. Factors affecting the availability of nutrients to plants. In:WALSH, L.W. e BEATON, J.D., ed. Soir testing and plant analysis. Madison, Soil Science Society of America, p.23-33.

CORSI, M. 1972. Estudo da produtividade e do valor nutritivo do capim elefante (Pennisetum purpureum, Schum), variedade napier submetido a diferentes frequências e alturas de corte. Piracicaba, ESAlQ-USP, 139p. (Tese de Doutoramento).

DAVIDSON, J.L. e F.L. MILTHORPE. 1966a. Leaf growth in Dactylis glomerata following defoliation. Annals of Botany, $0 \times f o r d, \quad 30(118): 173-184$. 
DAVIDSON, J.L. e F.L. MILTHORPE. 1966b. The effect defoliation on the balance in Dactylis glomerata. Annals of Botany, $0 x$ ford, $30(118): 185-198$.

DEINUM, B. e J.G.P. DIRVEN. 1972. Climate, nitrogen and grasses. 5. Influence of age, light intensity and temperature on the production and chimical composition of gongo grass (Brachiaria ruziziensis). Journal of Agricultural Science, Cambridge, 20:125-132.

DOVRAT, A.; E. DAYAN e H. VANKEULEN. 1980. Regrowth potential of shoot and roots of rhodes grass (Chloris gayana, Kunth) after defoliation. Netherlands Journal of Agricultural Science, Wageningen, 28(3):185-199.

EGUNJOBI, J.K. 1973. Studies on the primary productivity of regulary burnt tropical savana. Annals de l'université d'Abidjan, Série E, Abidjan, 6(2):157-169.

EMPRESA GOIANA DE PESQUISA AGROPECUARIA. 1979. Projeto Bovinos. Relatório Técnico Anual. EMGOPA. Goiània, p.40-62.

EMRICH, E.S. 1967. Competição entre cinco gramíneas forrageiras para formação de pastagens em solo de Cerrado. In: 2ạ Reunião Brasileira do Cerrado, Sete Lagoas, MG, P.209-221. 
EVANS, P:S. 1978. Plant root distribution and water use patterns of some pasture and crop species. Journal of Agricultural Research, Washington, 21:261-265.

FERRAZ, E.C. 1974. Apontamentos de fisiologia vegetal. Piracicaba, ESALQ-USP. 190 .

GARGANTINE, H. 1972. Efeito da calagem no pH e nos teores de cálcio mais magnésio e aluminio em perfís de solos de cerrados. Piracicaba, ESAlQ-USP. 78p (Tese de Doutoramento).

GALRÃo, E.Z. e A.S. LOPES. 1979. Deficiências nutricionais em solos de cerrado. In:V Simpósio sobre o cerrado, Brasilia, Editerra, p.595-614.

GOEDERT, W.J. 1979. Uso e manejo dos recursos naturais do cerrado: solo e clima. In: V Simpósio sobre o cerrado, Brasilia, Editerra, p.475-497.

GOMIDE, J.A. 1973. Fisiologia do crescimento livre de plantas forrageiras. In: Simpósio sobre manejo de pastagens. Piracicaba, ESALQ-USP. p.83-93. 
GOMIDE, J.A.; J.A. OBEID e L.R.A. RODRIGUES. 1979. Fatores morfofisiolögicós de rebrota do capim colonião (Panicum maximum). Revista da Sociedade Brasizeira de Zootecnia, Viçosa, $8(4): 532-562$.

GROF, B. 1981. The performance of Andropogon gayanus - legume associations in Colombia. Journal of Agricultural Science, Cambridge, $96: 233-238$.

HAGGAR, R.J. 1969. Use of comparison crops in grassland establishment in Nigeria. Experimental Agriculture, Cambridge, (5): $47-52$.

HAGGAR, R.J. 1970. Seasonal production of Andropogon gayanus, Kunth. I. Seasonal changes in yield components and chemical composition. Journal of Agricultural Science, Cambridge,74 (3) : $487-494$

HAGGAR, R.J. 1975. The effect of quality, source and time of application of nitrogen fertilizers on the yield and quality of Andropogon gayanus at Shika, Nigēria. Journal of Agricultural Science, Cambridge, 84(3):529-535. 
HOSEGOOD, P.G. 1963. The root distribution of kikuyu grass and wattle tress. East African Agricultural and Forestry Journal, Nairobi, $28: 60-61$.

HUMPHREYS, J.R. E A.R. ROBINSON. 1966. Subtropical grass growth. r. Relationship between carbohydrate accumulation and leaf area in growth. Queesland Journal of Agricultural and Animal Science, Brisbane,23(2):211-259.

JAMESON, D.A. 1963. Responses of individual plants to harvesting. The Botanical Review, Lancaster, 29(4):532-594.

JEWISS, 0.R. 1972. Tillering in grasses: its significance and control. Journal of the British Grassland Society, Aberystwyth, $27: 52-82$.

JONES, C.A. 1979. The potential of Andropogon gayanus, Kunth in the oxisol and ultisol savanas of tropical America. Herbage Abstracts, Aberystwyth, $\quad 1(49): 1-8$.

LANGER, R.H.M. 1959. A study of growth in swards of timothy and mea dow fescue. 11. The effects of cutting treatments. Journal of Agricultural Science, Cambridge, 52(3):273-281. 
LANGER, R.H.M. 1963. Tillering in herbage grasses. Herbage Abstracts, Aberystwyth, 36:437-440.

LANGER, R.H.M. 1972. How grasses grow. London, Edward Arnold, 60p. (studies in biology, 34).

LEOPOLD, A.C. 1949. The control of tillering in grasses by auxin. American Journaz of Botany, Lancaster, 36:141-148.

LIMA, F.A.M. 1976. Sistema radicular do capim elefante Pennisetum purpureum, Schum - cultivar mineirão, em diferentes espaçamentos e profundidades. O Solo, Piracicaba, $68(1)$ : $52-57$.

MAGALHĀES, A.C.N. 1979. Fotositintese. In: FERRI, M.G. FisioZogia Vegetal. São Paulo, EDUSP, Vol. I, p.117-163.

MALAVOLTA, E. et alii. 1964. Cultura e adubacão da cana-deaçücar. São Paulo, Instituto Brasileiro da Potassa, 368 .

MALAVoltA, E. 1976. Manual de Quimica Agricola: nutricão e fertizidade do solo. São Paulo, Ed. Agronômića Ceres, 528 . 
MALAVOLTA, E. 1980. Elementos de Nutrigão Mineral de Plantas. Sào Paulo, Ed. Agronōmica Ceres, 251 p.

MAY, L.H. 1960. The utilization of carbohydrate reserves in pasture plants after defoliation. Herbage Abstracts, Aberystwyth, $\quad 30(4): 239-245$.

MILTHORPE, F.L. e MOORBY, J. 1975. An introduction to crop physiology. London, Cambridge University Press, $202 p$.

NASCIMENTO Jr., D. e J.S. PINHEIRO. 1975. Desenvolvimento vegetativo do capim jaraguà. Revista da Sociedade Brasizeira de Zootecnia, Viçosa, 4(2):147-157.

NASCIMENTO, M.P.S.C.B. 1977. Alguns aspectos morfofisiológicos de três gramíneas de clima tropical. Viçosa, U.F.V., 41 . (Tese de Mestrado).

OTERO, J.R. 1952. Informagões sobre algumas plantas forrageiras. Rio de Janeiro, Serviço de Informação Agrícola, 313 .

PAULA, R.R.; J.A. GOMIDE; D. SYKES E J.R. CHAVES. 1959. Influência de diferentes sistemas de corte sobre o desenvolvimento radicular do capim gordura(Meilinis minutiflora, Beauv): Revista Ceres, Viçosa, 14(80):157-186. 
PEDREIRA, J.V.S. e C. BOIN. 1969. Estudo do crescimento do - capim elefante, variedade napier (Pennisetum purpureum Schum). Boletim da Indústria Animal, são Paulo, 26:263-273.

PEDREIRA, J.V.S. 1975. Hảbitos de perfilhamento do capim colonião, Panicum max $\vec{\imath} m u m$, Jacq. Boletim da Indústria Animal, são Paulo, $32(1): 111-114$.

PEDREIRA, J.V.S.; P. NUTI e B.E.S. CAMPOS. 1975. Competição de capins para produção de matéria seca. Boletim da Indústria Animar, São Paulo, $32(2): 319-323$.

PRIMAVESI, A. 1980. O Manejo Ecológico do Solo. São Paulo, Ed. Nobel. $541 \mathrm{p}$.

SINGH, R.D. e B.N. CHATtERJEE. 1966. Tillering of perenial grasses in the tropics of India. In: Congresso Internacional de Pastagens, São Paulo, p.1075-1079.

SINGH, R.D.; A. PREMCHAND e A. RAHAMAN. 1972. Herbage growth of pearl-millet grass hibrid when compared with others grasses. Indian Journal of Agricultural Science, New Delhi, $42(3)$ : $218-222$. 
TARDIN, A.C.; C.H. CALLES e J.A. GOMIDE. 1971. Desenvolvimento vegetativo do capim guatemala. Experientiae, Viçosa, $12(1): 1-13$.

THOMAS, D.; R.P. ANDRADE; W.COUTO; C.M.C. ROCHA E P. MOORE. 1981. Andropogon gayanus, var. bisquamulatus C.V. Planaltina. Principais características forrageiras. "Pesquisa Agropecuária Brasizeira, Brasilia, 16(3):347-355.

TOMPSETT, P.B. 1976. Factors affecting the flowering of Andropogon gayanus, Kunth. Responses to photoperiod, temperature and growth regulators. Annals of Botany, London 40:695-705.

VARTHA, E.W. 1972. Effects of shade on the growth of Poa pratensis and perinnial ryegrass. Journal of Agricultural Research, Melbourne, $16: 38-42$.

VILELA, H.; J.A. GOMIDE e M. MAESTRI. 1978. Efeito da idade da planta ao primeiro corte e dos intervalos entre cortes sobre o rendimento forrageiro, teor de carboidratos solūveis na base da planta, indice de ärea foliar e intercepção de luz em aveia forrageira. Revista da Sociedade Brasizeira de Zootecnia, Viçosa $7(1): 79-93$. 
YOUNGNER, V.B. 1972. Physiology of defoliation and regrowth. In:YOUNGNER, V.B. e MCKELL, C.M. ed. The biozogy and utilization of grasses. New York, Academic Press, p.292-303.

WILSON, J.R. e K.P. HAYDOCK. 1971. The comparative response of tropical and temperature grasses to varying levels of nitrogen and phosphoric nutrition. Australian Journal of Agricultural Research, Melbourne, 22:573-587.

WHITE, L.M. 1973. Carbohydrate reserves of grass: a review. Journal of Range Management, Portland, 26(1):13-18.

WHYTE, R.0. 1969. Las gramineas en la agricultura. Roma, FAO, $464 p$. 